\title{
Protective role of $\gamma \delta$ T cells in cigarette smoke and influenza infection
}

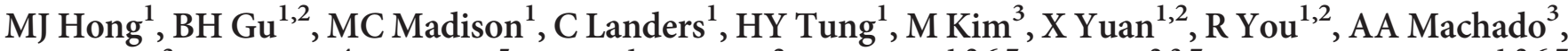

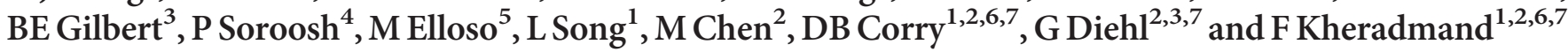

\begin{abstract}
Airborne pathogens commonly trigger severe respiratory failure or death in smokers with lung disease. Cigarette smoking compromises the effectiveness of innate immunity against infections but the underlying mechanisms responsible for defective acquired immune responses in smokers remains less clear. We found that mice exposed to chronic cigarette smoke recovered poorly from primary Influenza A pneumonia with reduced type I and II interferons (IFNs) and viral-specific immunoglobulins, but recruited $\gamma \delta$ Tcells to the lungs that predominantly expressed interleukin 17A (IL-17A). II-17a ${ }^{-1-}$ mice exposed to smoke and infected with Influenza A also recruited $\gamma \delta$ Tcells to the lungs, but in contrast to wild-type mice, expressed increased IFNs, made protective influenza-specific antibodies, and recovered from infection. Depletion of IL-17A with blocking antibodies significantly increased $T$-bet expression in $\gamma \delta$ T cells and improved recovery from acute Influenza A infection in air, but not smoke-exposed mice. In contrast, when exposed to smoke, $\gamma \delta$ T cell deficient mice failed to mount an effective immune response to Influenza $A$ and showed increased mortality. Our findings demonstrate a protective role for $\gamma \delta$ T cells in smokers and suggest that smoke-induced increase in IL-17A inhibits the transcriptional programs required for their optimal anti-viral responses. Cigarette smoke induces IL-17A expression in the lungs and inhibits $\gamma \delta$ T-cell-mediated protective anti-viral immune responses.
\end{abstract}

\section{INTRODUCTION}

Seasonal and pandemic influenza A infections are among the most important cause of chronic obstructive pulmonary disease (COPD) exacerbation, hospitalization, and respiratory failure. ${ }^{1}$ Epidemiological studies support increased influenza-associated all-cause mortality in current and former smokers compared with life-time nonsmokers. ${ }^{2}$ The extent of lung disease is an important contributing factor for hospitalization and the need for mechanical ventilation in COPD patients, whereas failure to mount appropriate anti-viral immune responses has also been shown to have a role in poor clinical outcomes. ${ }^{3,4}$ Active smokers without COPD inoculated with live attenuated influenza show reduced interleukin (IL)-6, and increased viral RNA in the nasal mucosa when compared with nonsmokers, indicating that cigarette smoke may directly inhibit lung epithelial responses to influenza. ${ }^{4}$ Despite the influx of innate and acquired immune cells to the lungs, active smokers are highly susceptible to viral and bacterial infections. ${ }^{5}$ The adverse response to cigarette smoke may be in part, due to the excessive accumulation of particulate matter in lung macrophages and airway epithelial cells ${ }^{6}$ that could render them ineffective against infection and the lungs more susceptible to epithelial injury. ${ }^{7,8}$ Therefore, although cigarette smoke could alter local innate immune responses to infection in the lungs, the effect of smoke on acquired immunity in the lung mucosa remains unknown.

Animal models of cigarette smoke-induced lung disease have shown reduced expression of interferons (IFNs) and increased IL- 6 and tumor necrosis factor- $\alpha$ in the lungs in response to influenza infection. ${ }^{9,10}$ Further, enhanced lung inflammation and cytokine expression in smoke-exposed mice has shown to promote susceptibility to influenza infection. ${ }^{11,12}$ Several experimental models, ${ }^{9,13,14}$ together with clinical studies of viral-induced COPD exacerbation ${ }^{15,16}$ support strong evidence

${ }^{1}$ Section of Pulmonary and Critical Care, Department of Medicine, Baylor College of Medicine, Houston, Texas, USA. ${ }^{2}$ Department of Pathology and Immunology, Baylor College of Medicine, Houston, Texas, USA. ${ }^{3}$ Department of Molecular Virology and Microbiology Baylor College of Medicine Houston Texas, USA. ${ }^{4}$ Janssen R\&D Immunology, San Diego, California, USA. ${ }^{5}$ Janssen R\&D Immunology, Spring House, Pennsylvania, USA. ${ }^{6}$ Center for Translational Research in Inflammatory Diseases, Michael E. DeBakey VA, Houston Texas, USA and ${ }^{7}$ Biology of Inflammation Center, Baylor College of Medicine, Houston, Texas, USA. Correspondence: F Kheradmand or G Diehl (farrahk@bcm.edu or Gretchen.Diehl@bcm.edu) 
for ineffective anti-viral immunity in response to cigarette smoke which can be augmented by genetic susceptibility factors. ${ }^{17-19}$

Systemic and lung-specific cellular responses to cigarette smoke result in activation of several key innate immune cells and complement proteins that accelerate pathogenic myeloidderived dendritic cell recruitment into the lungs. ${ }^{20-23}$ Activated myeloid-derived dendritic cells promote the differentiation of Th1, Th17 cells in human emphysema ${ }^{24}$ and chronic cigarette smoke enhances IL-17 expression in $\gamma \delta \mathrm{T}$ cells in the lungs. ${ }^{22}$ Cytokines (e.g., IL-17A, IFN- $\gamma$, IL-1 $\beta$, etc.) and chemokines such as CXCL1 (KC), CXCL8 (IL-8), CXCL9 (Mig), and CXCL10 (IP-10) have been shown to induce proteinases in the lungs that are associated with emphysema development. ${ }^{25-27}$ We have previously shown that $I l-17 a$ deficiency attenuates, although constitutive overexpression of this cytokine exacerbates, smoke-induced emphysema. ${ }^{21}$ Further, a significant subset of $\gamma \delta$ T cells express IL-17A and have a tropism for lung mucosa in mice exposed to smoke, whereas deficiency in $\gamma \delta \mathrm{T}$ cells results in exaggerated lung inflammation and emphysema in mice. ${ }^{21}$ Several cytokines and chemokines expressed by innate immune cells in chronic smoke exposure and respiratory viral infection have been shown to induce lung injury; ${ }^{28}$ however, the role of cigarette smoke-induced recruitment of $\gamma \delta$ $\mathrm{T}$ cells and IL-17A expression in response to respiratory viral infection remains less clear.

Although influenza infection often causes a mild-tomoderate degree of respiratory illness in immunocompetent hosts, increased morbidity and mortality in response to acute infection in human smokers has been well documented. ${ }^{29}$ In this study, we set out to examine the impact of chronic smoke on lung immune cells and physiological outcome following influenza infection using a well-established mouse model of smoke induced lung disease. ${ }^{22}$ We have previously found that Th17, and $\gamma \delta$ T cells have critical roles in smoke induced lung disease, ${ }^{21}$ therefore in this study, we examined their role in response to cigarette smoke and influenza infection. We found that mice exposed to smoke recover poorly from influenza pneumonia and fail to produce high titers of hemagglutinin (HA)-specific protective antibodies. These findings were associated with the reciprocal expression of IFN- $\gamma$ and IL$17 \mathrm{~A}$ in CD 4 and $\gamma \delta \mathrm{T}$ cells in the lungs. Mice that lack $\gamma \delta \mathrm{T}$ cells $\left(T c r \delta^{-1-}\right)$ exposed to smoke and influenza pneumonia showed increased mortality, indicating a protective role for $\gamma \delta \mathrm{T}$ cells in smoke and influenza infection. Finally, we determined the mechanism for the failure of mucosal $\gamma \delta$ T cells in protective immunity in mice exposed to chronic smoke.

\section{RESULTS}

Increased morbidity in smoke-exposed mice infected with influenza A

Smokers with structural lung disease are at an increased risk for hospitalization and death when infected with respiratory viruses. ${ }^{16,30-32}$ To determine how cigarette smoke-induced lung disease can affect acquired immune responses to influenza, we designed a preclinical model that closely emulates acute respiratory infection in smokers. Mice were exposed to three months of Smoke (Smk) or ambient air (Air), followed by primary infection with influenza A virus ( $\mathrm{H} 3 \mathrm{~N} 2$; sublethal dose of $\left.25 \mathrm{TCID}_{50}\right){ }^{33}$ Two days following inoculation, mice received two additional weeks of cigarette smoke prior to analysis (Supplementary Figure S1A online). Mice exposed to 12 weeks of cigarette smoke had lower weight and initially lost less body mass when compared with air exposed mice (Supplementary Figure S1B). As expected, smoke-exposed mice infected with Influenza A (Smk/Flu), lost significantly more weight on day 10 , and showed increased time to recovery from the acute infection, as measured by weight gain, when compared with mice exposed to Air and infected with the same dose of Influenza A (Air/Flu) (Figure 1a). Consistent with an exaggerated but ineffective immune response, bronchoalveolar lavage (BAL) fluid collected in Smk/Flutreated mice showed increased neutrophilic inflammation (Figure 1b), and matrix metalloproteinase (MMP)2 and MMP9 secretion, and MMP12 expression compared with Air/Flu and uninfected air- or smoke-exposed groups (Supplementary Figure S2A, B). Moreover, semiquantitative histological scoring of the lungs demonstrated more severe peri-bronchial inflammation, in the lungs of Smk/ Flu-treated mice compared with the Air/Flu group, and increased mucin production as detected by Periodic AcidSchiff staining (Figure 1c and d, and Supplementary Figure S3). As mice were infected with a sublethal dose of influenza, we expected no or limited mortality after influenza infection. Instead, we observed increased mortality in Smk/Flu-treated mice with $14 \%$ (6 of 43) of the Smk/Flu-treated group died compared with $1.75 \%$ (1 of 58) of the Air/Flu group.

Whole lung mRNA expression showed significantly decreased type I IFNs and cytotoxic enzymes including Granzyme b $(G z m b)$ in Smk/Flu compared with Air/Flutreated group (Figure 1e). In contrast, the concentration of three pro-inflammatory cytokines, tumor necrosis factor- $\alpha$, IL6 , and $\mathrm{KC}$ were increased in the lungs, whereas we found relative suppression of monocyte-related factors in particular $\mathrm{Ccl} 3$ and $\mathrm{Ccl} 4$ (macrophage inflammatory protein- $1 \alpha$ (MIP-1 $\alpha$ ) and MIP-1 $\beta$ ), and Ccl5 (RANTES), in Smk/Flu-treated group when compared with Air/Flu-treated mice (Figure 1f).

\section{Reciprocal expression of type I-II IFNs and IL-17A}

We next examined lung specific protective immune responses to influenza in our smoke/flu model. Comprehensive characterization of single cells isolated from lungs showed increased IL-17A, but decreased IFN- $\gamma$ expression in Smk/Flu mice when compared with Air/Flu (Figure 2a and Supplementary Figure S4). Whole lung mRNA expression showed significantly decreased type II IFNs and their associated genes including IFN-induced protein with tetra-tricopeptide repeat 3 (Ifit3), transcription factor Irf7 (Figure 2b) that is linked to susceptibility to influenza. ${ }^{34}$ To further characterize the cellular expression profile of IFN- $\gamma$ and IL-17A in the lungs, we next performed intracellular cytokine (ICC) of $\mathrm{CD}^{-}$and $\mathrm{CD}^{+}$ immune cells in whole lung, spleen, and draining lymph node. 
a

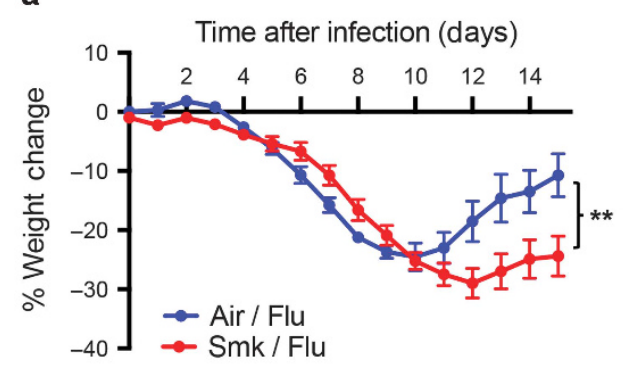

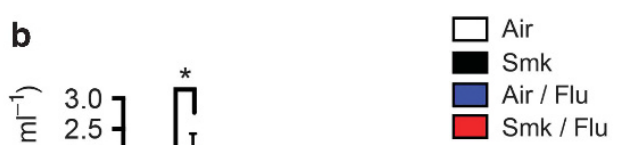

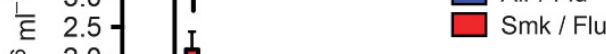

C
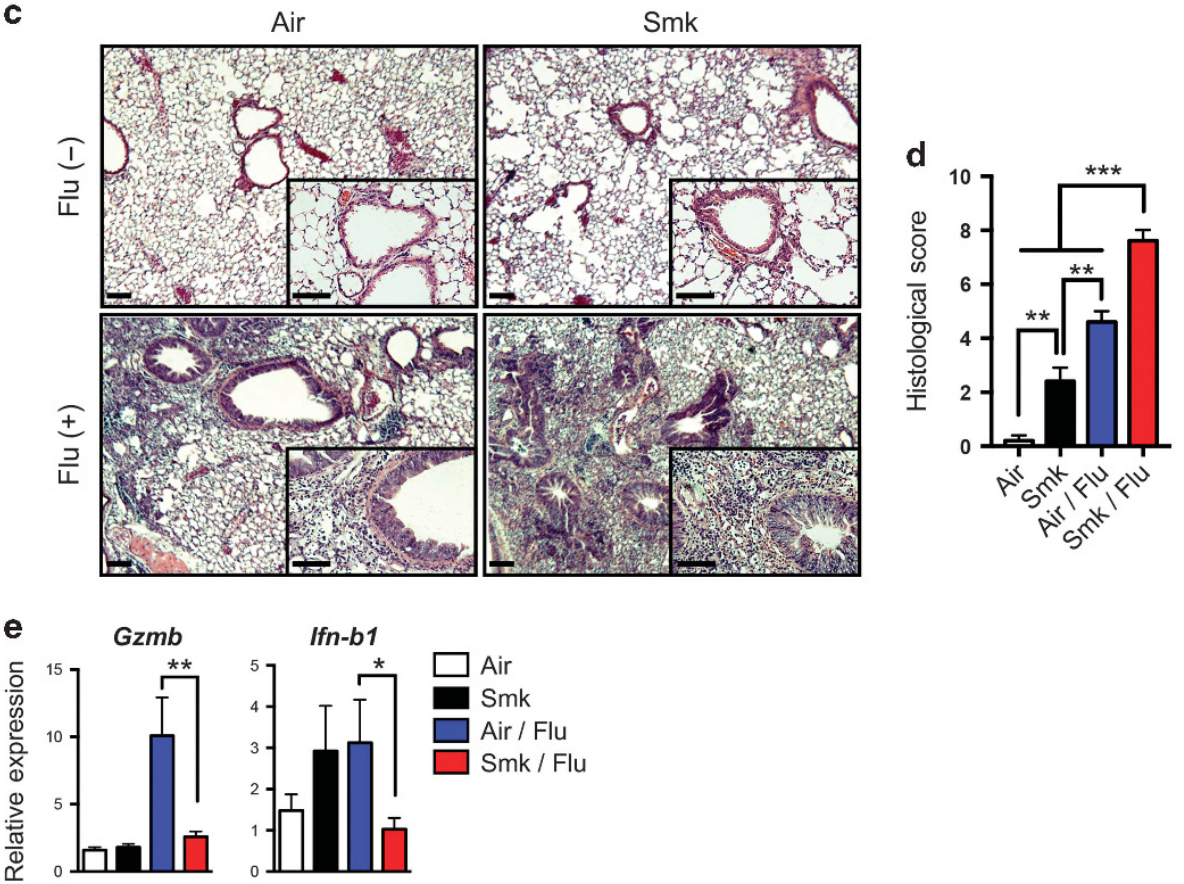

$\mathbf{f}$

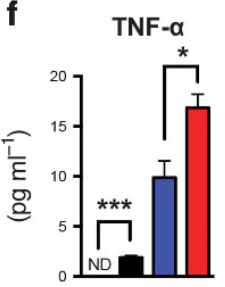

IL-6
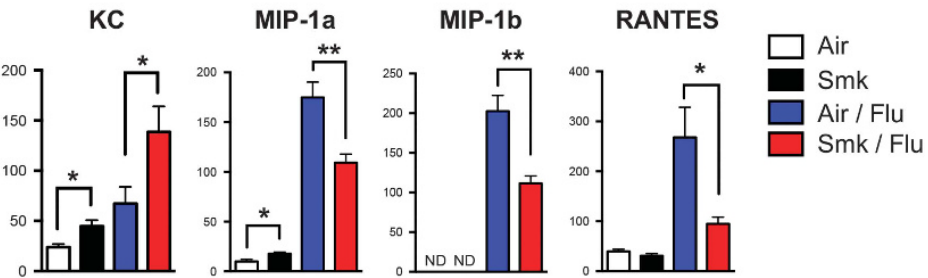

Figure 1 Cigarettes smoke-exposed mice infected with influenza A show increased lung inflammation. Mice were exposed to air (Air) or smoke (Smk) for 3 months and were infected with $\mathrm{H} 3 \mathrm{~N} 2(\mathrm{~A} / \mathrm{HK} / 8 / 68)$ at $25 \mathrm{TCID}_{50}\left(<\mathrm{LD}_{2.5}\right.$; sublethal). (a) Representative body weight reduction (percent change) on day 14 following influenza infection (Air/Flu, $n=8 ;$ Smk/Flu, $n=7$ ). Data are representative of three independent studies, (b) total bronchoalveolar lavage (BAL) cell number, and differential: macrophages (Mac), eosinophil (Eos), neutrophils (Neu), and lymphocytes (Lym) on day 14 following influenza infection. ( $n=4$ or 5 mice per group). (c) Histopathological analysis of the lung tissue collected on day 11 after influenza infection and pathology scores quantified (d) $\left(n=5\right.$ mice per group) ${ }^{\star \star} P<0.01,{ }^{\star \star \star} P<0.001$. Representative $(\times 200)$ hematoxylin and eosin (H\&E) micrographs. Scale bar, $100 \mu \mathrm{m}$. (e) Relative expression of anti-viral defense granzyme b (Gzmb), and Interferon b1 (Ifn-b1) were measured using mRNA isolated from whole lung on day 14 following influenza infection. (f) Cytokines and chemokines were measured in BAL fluid (tumor necrosis factor (TNF)- $\alpha$ ) or whole lung homogenates supernatant on day 14 following influenza infection $(n=8$ in each group). Results represent mean \pm s.e.m. Significance was determined using the Student's $t$-test with Bonferroni correction for multiple comparisons ${ }^{\star} P<0.05,{ }^{\star *} P<0.01$.

We found a reciprocal expression of IL-17A and IFN- $\gamma$ in the lung $\mathrm{CD}^{+} \mathrm{T}$ cells but not spleen or lung draining lymph nodes (Supplementary Figures S6A-F). Further analysis of cytokine expression revealed significant changes in IL-17A and IFN- $\gamma$ expression in $\mathrm{CD}^{+}$but not $\mathrm{CD}^{-}$cells in the lungs (Supplementary Figure S7). To determine the contribution of different IL-17A expressing T cell subsets, we next used flow cytometry to assess IL-17A and IFN- $\gamma$ expression in $\gamma \delta$, CD4, and CD8 T cells in each of the four experimental groups. Overall, there were no significant differences in the relative abundance of CD4, CD8, or $\gamma \delta \mathrm{T}$ cells between Air/Flu and Smk/Flu-treated mice (Supplementary Figures S8A and B), and $\gamma \delta \mathrm{T}$ cells were the predominant IL-17A expressing $\mathrm{T}$ cells. (Supplementary Figure S8C). However, ICC analyses of lung 
a

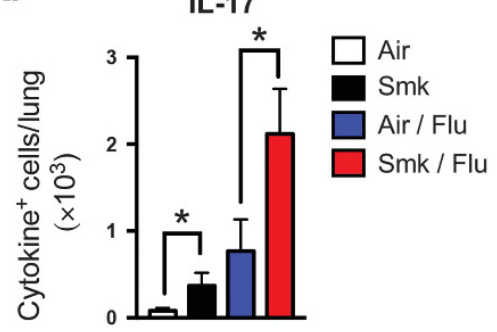

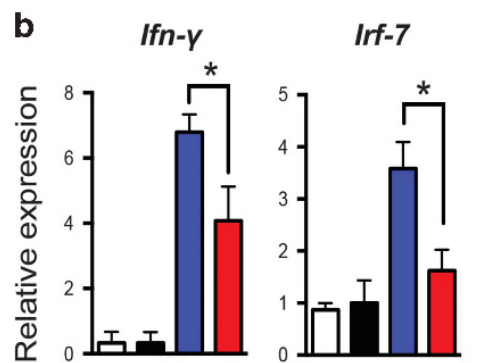

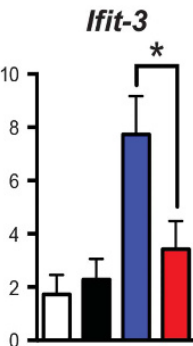

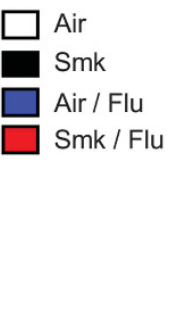

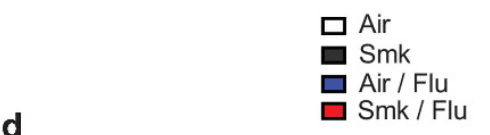

C
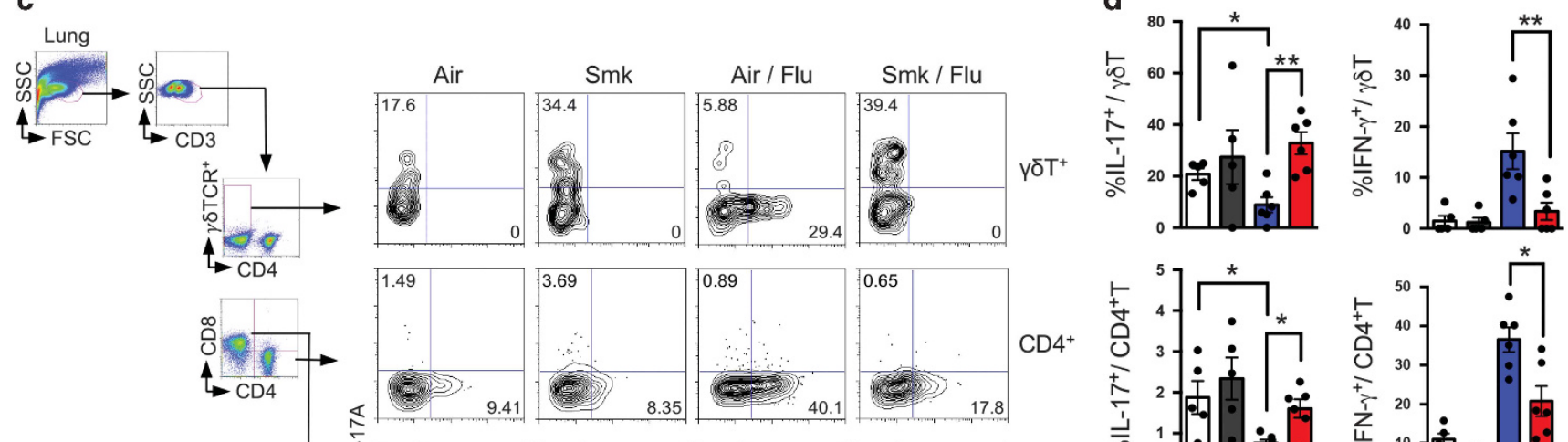

$\mathrm{CD} 4^{+}$
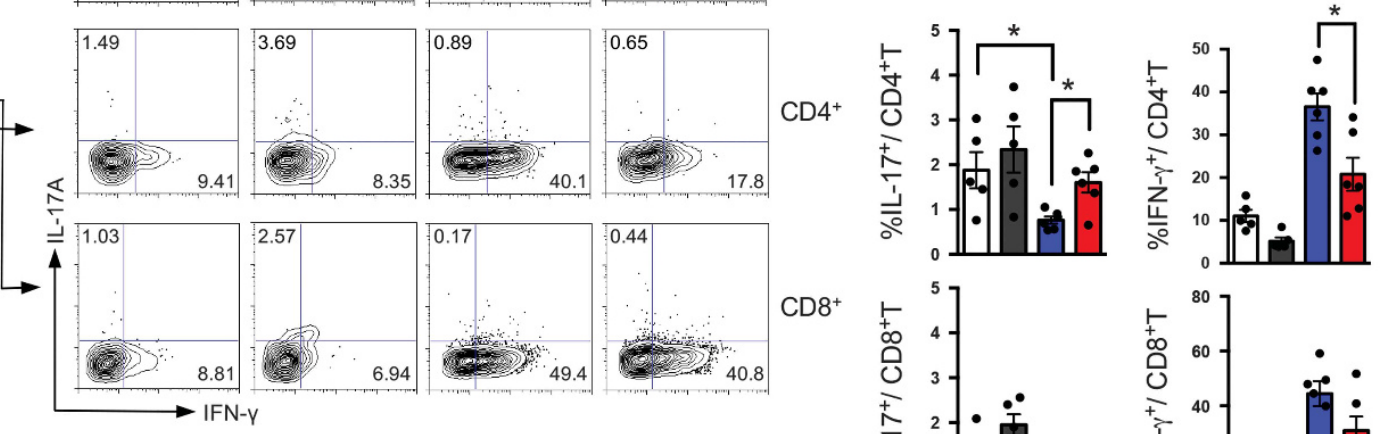

$\mathrm{CD}^{+}$
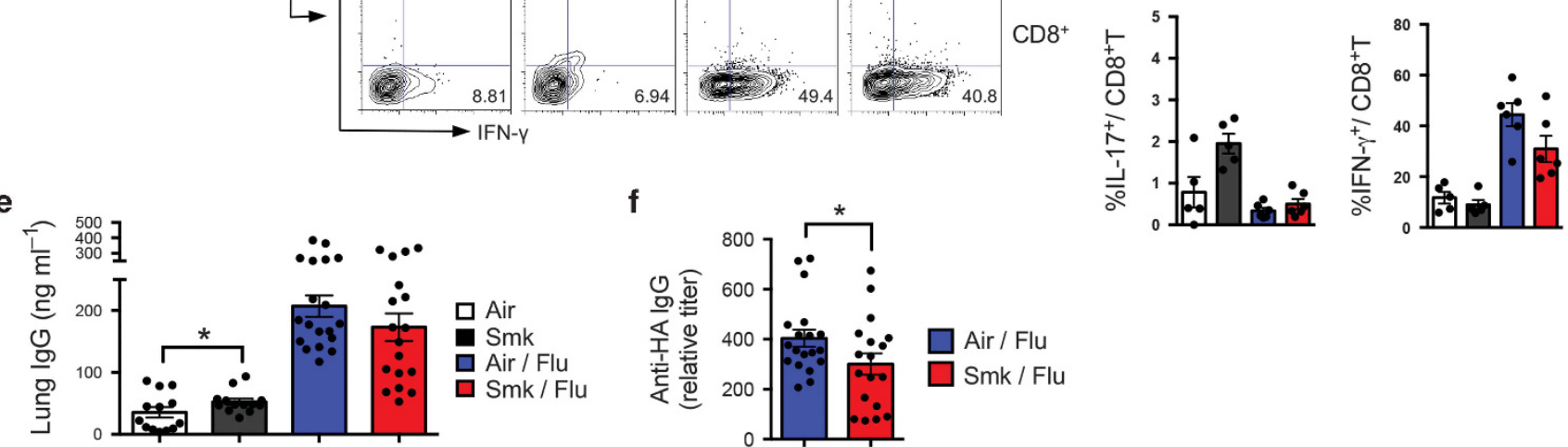

f
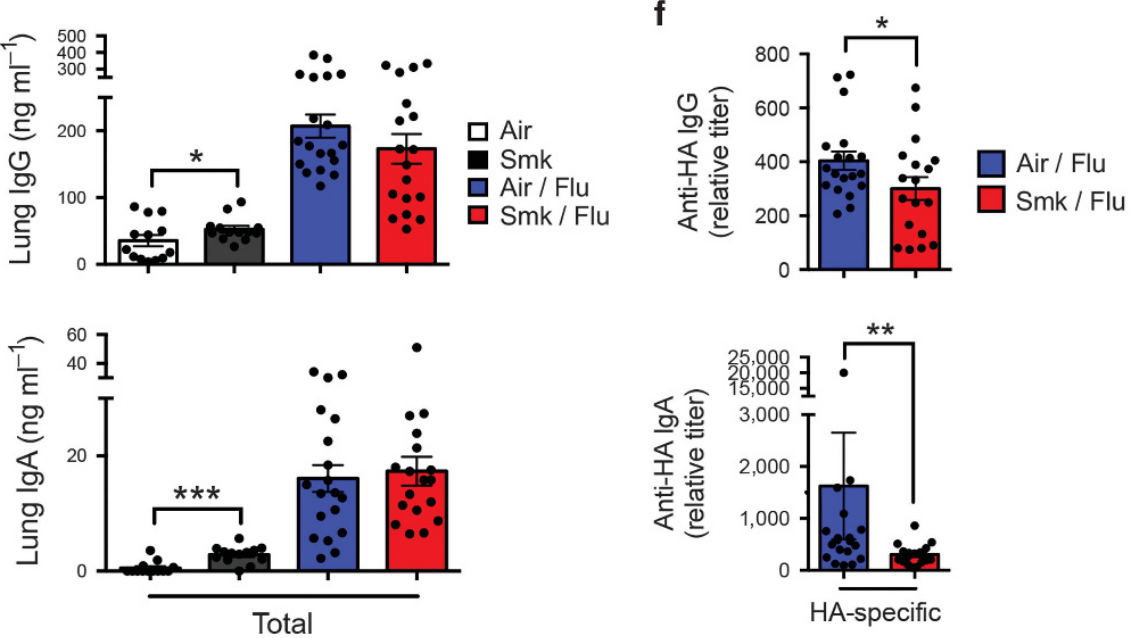

Figure 2 Decreased protective immunity in influenza-infected, smoke-exposed mice. (a) Enzyme linked immune-spot (ELISpot) quantification of interleukin (IL)-17A using single cells isolated from whole lung in the same group of mice on day 14 following influenza infection $\left(n=4\right.$ per group) ${ }^{*} P<0.05$. (b) Whole lung mRNA expression of Ifn- $\gamma$, IIf7, and Ifit-3in the same groups of mice described in Figure 1. (Air, smoke (Smk), Air/Flu, Smk/Flu, $n=5$ ) (c) Representative intracellular cytokine (ICC) staining analyses of lung $\gamma \delta \mathrm{T}^{+}, \mathrm{CD} 4^{+} \mathrm{T}$, and $\mathrm{CD} 8^{+} \mathrm{T}$ cells gated on total lung $\mathrm{CD} 3^{+}$lymphocytes. (d) Cumulative data IL-17A and interferon (IFN)- $\gamma \%$ ICC in $\gamma \delta$, CD4, and CD8 T-cell subsets isolated from the lungs in the same group of mice $(n=5$ or 6 per group). (e) Quantification of total IgG, IgA, or (f) anti-hemagglutinin (HA)-specific IgG, or IgA antibody in the lung homogenates samples 14 days after influenza infection. Pooled data obtained from at least three different experiments (Air, $n=13$ : Smk, $n=13$; Air/Flu, $n=19$, Smk/Flu, $n=18$ ). Significance was measured using the Student's $t$-test with Bonferroni correction for multiple comparisons ${ }^{\star} P<0.05,{ }^{\star *} P<0.01,{ }^{* \star} P<0.001$.

$\mathrm{CD}^{+} \mathrm{T}$ cells showed increased abundance of $\gamma \delta$ and $\mathrm{CD} 4 \mathrm{~T}$ cells that express IL-17A in Smk and Smk/Flu compared with Air or Air/Flu mice (Figure 2c and d). Influenza infection induced significant IFN- $\gamma$ production in $\gamma \delta$, CD4, and CD8 T cells; however, this response was severely blunted in CD4 and $\gamma \delta \mathrm{T}$ cells from smoke-exposed mice (Figure $2 \mathrm{c}$ and d). 
Interestingly, smoke did not blunt IFN- $\gamma$ production by $\mathrm{CD} 8 \mathrm{~T}$ cells (Figure 2c and d), indicating that the phenotypic differences we observed were primarily due to the impact of smoke on CD4 and $\gamma \delta$ T cells.

As neutralizing antibodies have an important role in immune defense against influenza, ${ }^{35}$ we next examined whether chronic cigarette smoke could adversely affect antigen-specific antibody production in our model. Total IgG and IgA concentrations in the lung homogenates of uninfected smoke-exposed mice were significantly greater than the Air control group (Figure 2e). However, protective influenza antibody (e.g., HA-specific IgG and IgA) titers in the Smk/Flu treatment group were a

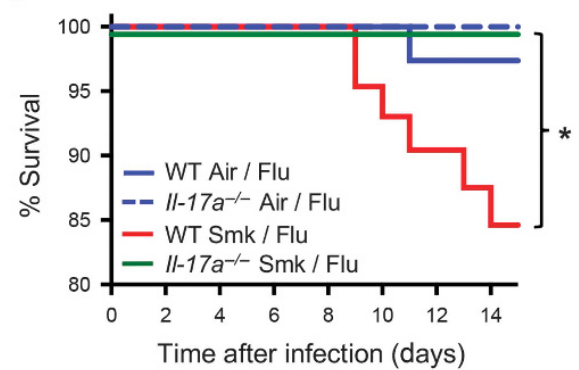

c

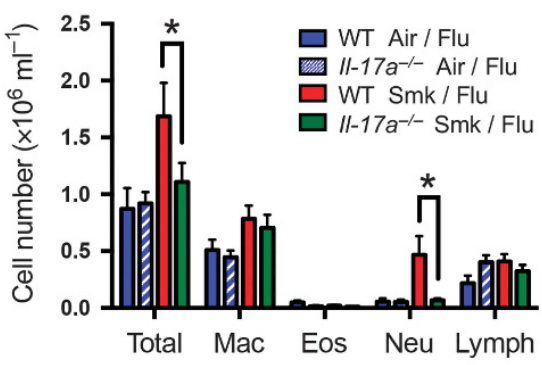

b

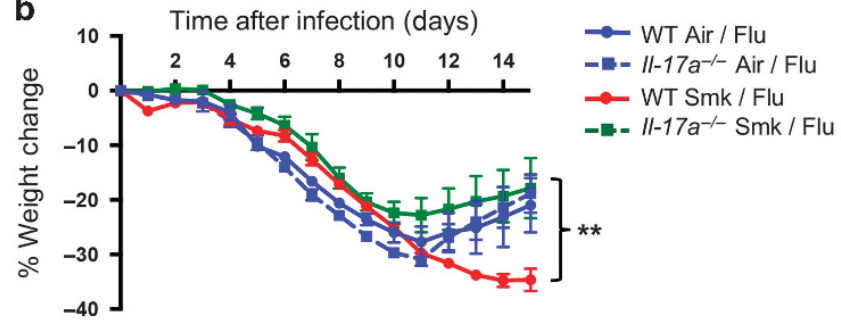

d

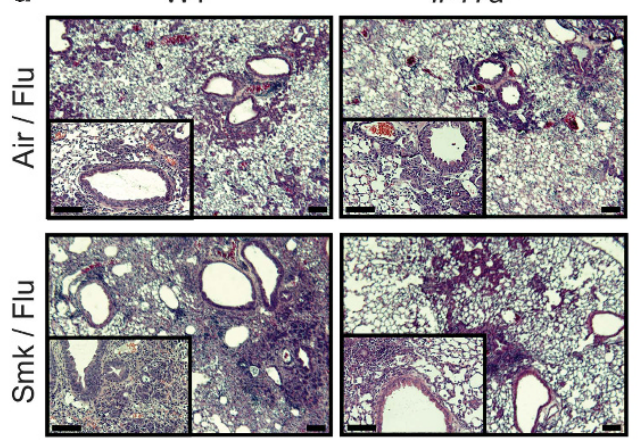

e

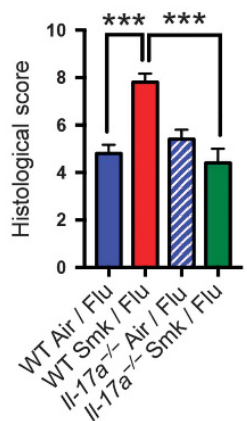

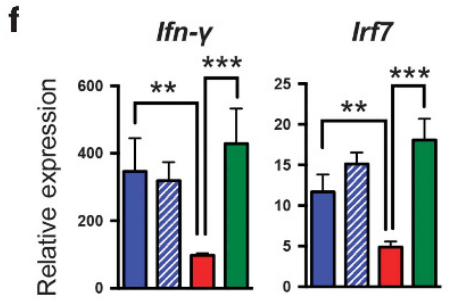

g

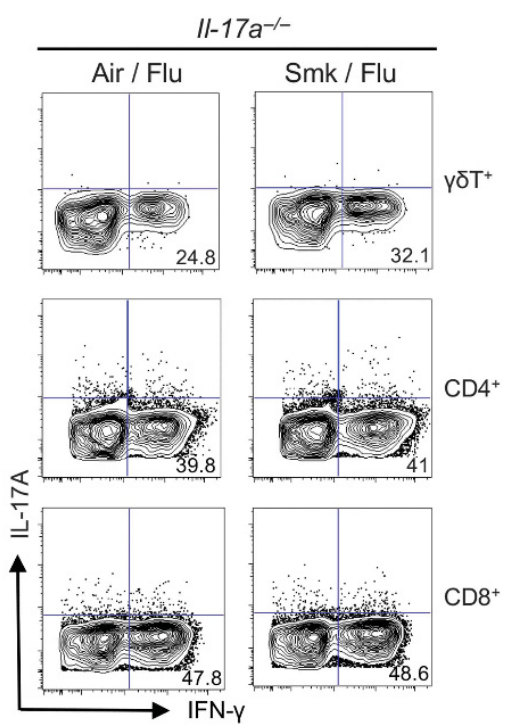

Ifit-3 Gzmb

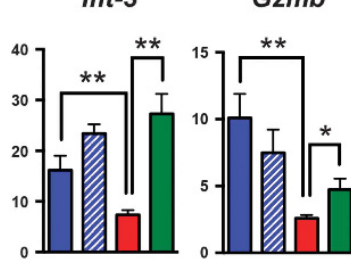

$\square$ WT Air / Flu

II-17a $a^{-/}$Air / Flu

$\square$ WT Smk / Flu

$\square / 1-17 a^{-/-}$Smk / Flu

h
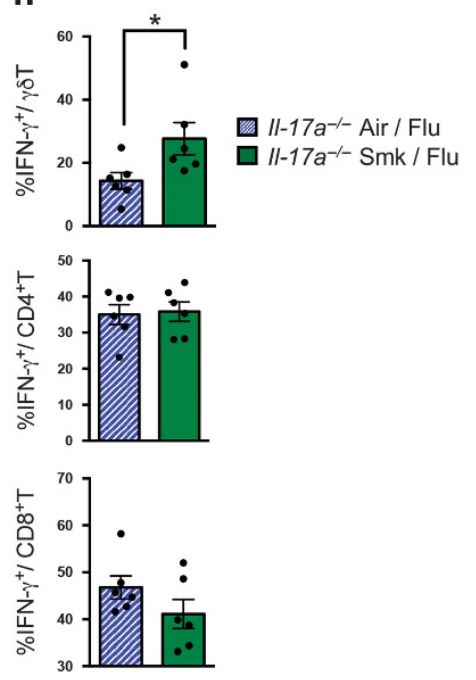
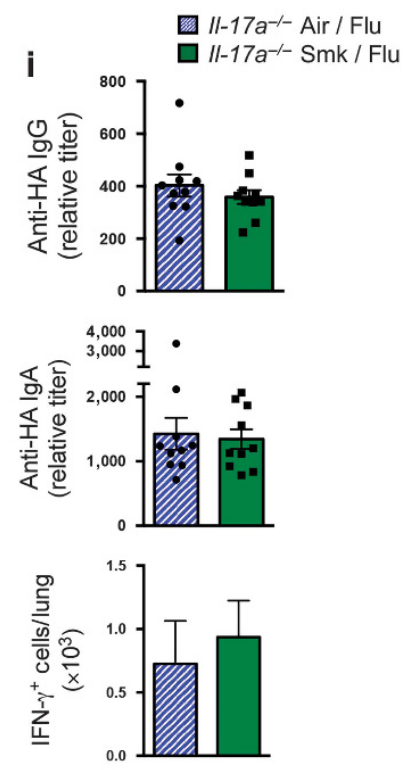
significantly reduced when compared with the Air/Flu group (Figure 2f). These data indicate that despite chronic inflammatory conditions, specific anti-viral immunity (e.g., HA-specific IgG and IgA antibodies) is compromised in mice exposed to chronic smoke.

IL-17A deficiency protects smoke-exposed mice from flu We have previously shown that IL-17A deficient $\left(\mathrm{Il}-17 a^{-/-}\right)$ mice develop attenuated lung inflammation in response to cigarette smoke and are protected against emphysema, whereas airway overexpression of IL-17A results in exaggerated responses to cigarette smoke. ${ }^{21}$ As we detected a reciprocal relation between IL-17A and IFN- $\gamma$ expression in $\gamma \delta$ and CD $4 \mathrm{~T}$ cells in the lungs of Smk/Flu-treated mice, we next sought to determine whether lack of IL-17A could protect smokeexposed mice from severe and/or ineffective immune response to acute flu infection. In contrast to wild-type (WT) animals, Smk/Flu-treated $I l-17 a^{-1-}$ mice were phenotypically similar to air-treated mice and did not show increased weight loss, did not develop respiratory failure, and showed rapid recovery from influenza infection (Figure $\mathbf{3 a}$ and $\mathbf{b}$ ). Consistent with improved recovery in the absence of IL-17A, Smk/Flu-, and Air/Flu-treated Il-17a $a^{-1-}$ mice showed comparable infiltration of inflammatory cells in BAL (Figure 3c). In sharp contrast to WT mice exposed to Smk/Flu (Figure 1c), lung histology also showed lack of exaggerated inflammatory cells in the lung parenchyma and attenuated peri-bronchiolar inflammation and airway wall thickening (Figure 3d and e). Whole-lung gene expression analyses of $\mathrm{Il}-17 a^{-/-}$Smk/Fluand Air/Flu-treated mice also showed similar expression of type I and II IFNs, and their associated transcription factors (e.g., Irf7 and Ifit3), as well as Gzmb indicting that appropriate viralspecific immune responses are not inhibited by smoke in the absence of IL-17A expression (Figure 3f).

To determine if lack of IL-17A concomitant with smoking led to recovered viral specific T-cell responses, we next examined IFN- $\gamma$ production in different T-cell subsets as described above. ICC analyses of lung lymphocytes from influenza-infected, smoke- or air-exposed $\mathrm{Il}-17 \mathrm{a}^{-/-}$mice showed comparable induction of IFN $-\gamma$ in CD 4 and CD8 T cells (Figure $3 \mathrm{~g}$ and Supplementary Figure S9A). In particular, $\gamma \delta$ $\mathrm{T}$ cells in smoke-exposed $\mathrm{Il}-17 \mathrm{a}^{-/-}$mice infected with influenza showed significantly increased IFN- $\gamma$ expression when compared with air exposed animals infected with influenza (Figure 3h). Moreover, $\mathrm{Il}-17 \mathrm{a}^{-/}-\mathrm{Smk} / \mathrm{Flu}-$ treated mice produced protective HA-specific IgG and IgA antibodies (Figure 3i and Supplementary Figure S9B), which is consistent with intact IFN- $\gamma$ producing cells in the lungs. Together these findings indicate that in the absence of systemic IL-17A, smoke-exposed mice infected with influenza can appropriately increase type I and II IFNs leading to protection from influenza.

\section{IL-17A mediates early influenza clearance but causes excessive lung injury}

To determine whether IL-17A has an important role in viral clearance, we next measured lung influenza A viral titers during peak, mid, and late viral replication phases $(6,8$, and 10 days post infection, respectively). ${ }^{36}$ At peak replication (day 6), compared with WT, Il-17a-/- Air/Flu- or WT Smk/Flutreated mice, $\mathrm{Il}-17 a^{-/-}$Smk/Flu showed a 10-fold increase in viral titers, indicating IL-17A is required for early clearance of influenza in smoke-exposed mice (Figure 4a). However, during the late viral replication phase (day 10), WT Smk/Flu-treated mice showed $\sim 100$-fold higher viral titers, indicating significant failure to clear viral infection compared with WT Air/Flu-treated mice (Figure 4a).

All groups at peak influenza amplification time points showed a similar increase in IFN- $\gamma$ expression, notably however when compared with WT Air/Flu condition, we found significant increase in IL-17a concentration only in the lungs of WT mice in Smk/Flu group, indicating an inappropriate cytokine response to influenza infection (Supplementary Figure S5). WT mice treated with Smk/Flu showed lower viral titers on day 6 when compared with $\mathrm{Il}-17 \mathrm{a}^{-/-}$group (Figure 4a); however, by day 10, and despite continued exposure to cigarette smoke, influenza was not detectable in nearly half of $I l-17 a^{-/-}$mice (4/10), compared with only 1 out of 10 in WT mice in Smk/Flu group (Figure 4a). We also found that by day 8 , viral titers were similar between the groups, whereas lung weight and hemorrhage score were less severe in $\mathrm{Il}-17 \mathrm{a}^{-/-}$mice (Figure $4 \mathrm{c}$ and $\mathrm{d}$ ).

We next measured lung weight and assigned hemorrhagic scores ${ }^{37,38}$ to quantify acute lung inflammation and injury using the same viral replication time points (e.g., day 6-, 8-, and 10-day) in WT and Il-17A ${ }^{-1-}$ mice exposed to Air/Flu and Smk/Flu. Consistent with the notion that IL-17A induces lung damage after influenza infection, $I L-17 a^{-/-}$Smk/Flu-treated

Figure $3 \quad 1 /-17 a^{-/-}$mice exposed to smoke generate protective immune response against influenza. II-17a ${ }^{-/-}$mice were exposed to air (Air) or smoke (Smk) for three months and were infected with sub-lethal H3N2 per protocol (Supplementary Figure S1). (a) Kaplan-Meier Survival curve for influenzainfected wild-type (WT) and IL-17a ${ }^{-1-}$ (Air/Flu and Smk/Flu) mice. (WT Air/Flu, $n=58$; WT Smk/Flu, $n=43$; $I 1-17 a^{-1-}$ Air/Flu, $n=20, I I-17 a^{-1-}$ Smk/ Flu, $n=30$ ) determined by log-rank test. ${ }^{*} P<0.05$ WT Smk/Flu vs. $I I-17 a^{-1-}$ Smk/Flu. (b) Percent body weight changes were monitored in the same group of mice for 14 days following influenza infection. (c) Representative experiments showing total bronchoalveolar lavage (BAL) cell count and differential (macrophages (Mac), eosinophil (Eos), lymphocytes (Lym), and neutrophils (Neu)) in the same group of mice described in (a) ( $n=7$ or 8 per group) on day 14 following influenza infection. (d) Representative hematoxylin and eosin (H\&E) stain of lung tissue section 14 days after influenza A infection and histology scoring (e) $\left(n=5\right.$ mice per group). Scale bars, $100 \mu \mathrm{m}$. ${ }^{* * *} P<0.001$ (f) mRNA expression in total lung cells from WT and II-17a ${ }^{-/-}$ in the same group of mice ( $n=6$ or 8 per group). (g) Representative flow cytometry intracytoplasmic cytokine (ICC) plots and (h) cumulative frequencies for interleukin (IL)-17A and interferon (IFN)- $\gamma$ production in each of the T-cells subsets isolated from lungs in 2 different groups of $I-17 a^{-/-}$mice as indicated before ( $n=6$ in each group). (i) Quantification of anti-hemagglutinin (HA)-specific IgG or IgA antibody using lung homogenates in the same groups. Pooled data from two separate experiments ( $n=5$ per group). IFN- $\gamma$ measured in whole lung homogenates using enzyme linked immune-spot (ELISpot) in the same group of mice ( $n=6$ per group). Results are mean \pm s.e.m. ${ }^{\star} P<0.05,{ }^{\star \star} P<0.01,{ }^{\star \star \star} P<0.001$ as determined by the Student's $t$-test and Bonferroni correction. 
mice showed significantly lower lung hemorrhage score at day10 compared with WT mice treated the same way (Figure 4b-d). Further, $I L-17 a^{-/-}$Smk/Flu-treated mice showed significantly lower lung weight than WT mice (Figure 4d).

\section{Anti-IL-17A treatment attenuates lung inflammation}

The above results suggested a potential role for IL-17A in limiting effective immune defense against primary influenza pneumonia. Therefore, we next examined the therapeutic

a

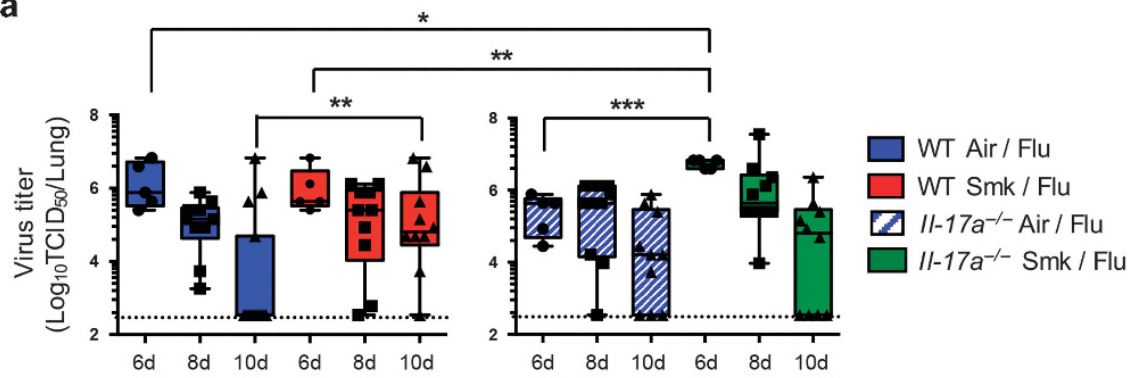

b $\quad$ WT

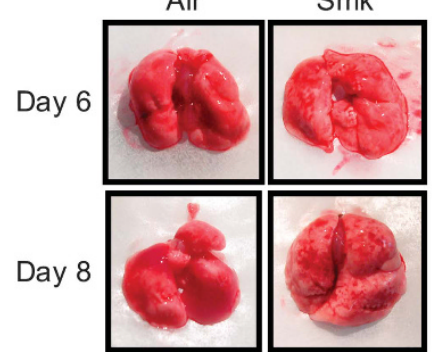

$\frac{11-17 a^{-/-}}{\text {Air Smk }}$

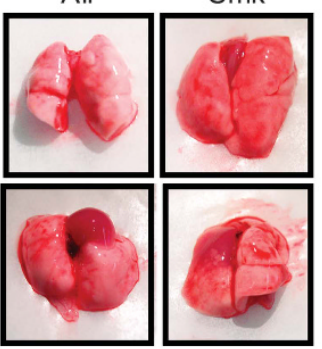

Day 10
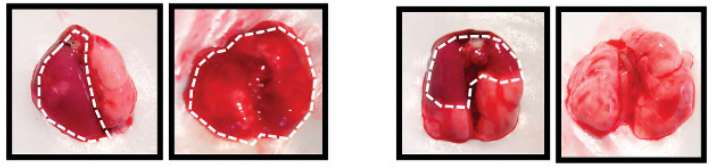

C

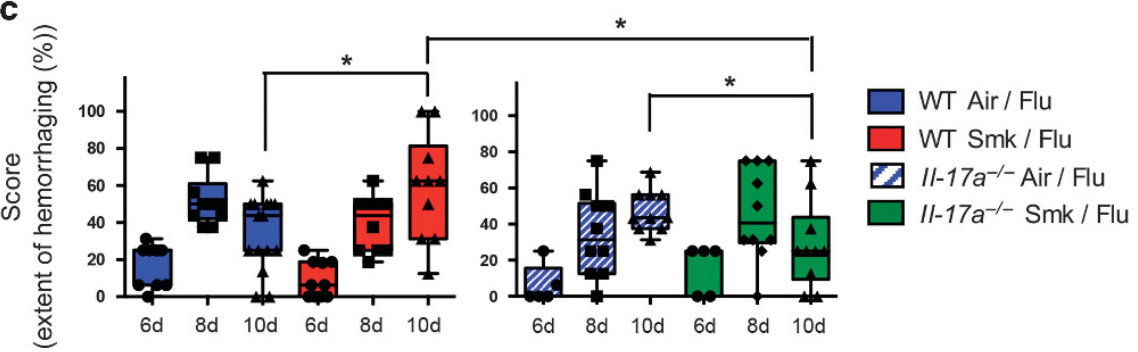

d

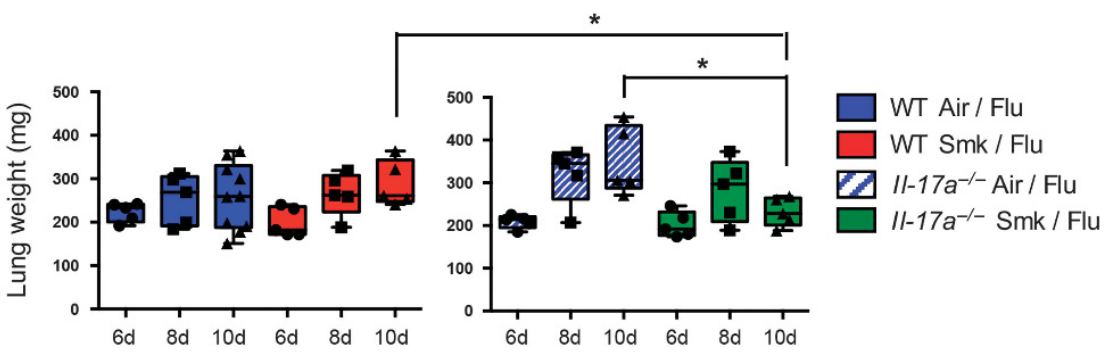

Figure 4 Increased late stage lung viral load and damage in chronic cigarette smoke. Mice (wild-type (WT) and II-17a ${ }^{-/-}$mice) in Air/Flu and smoke (Smk)/Flu groups were euthanized at peak (day 6), mid (day 8), and late (day 10) post sublethal dose (25 TCID so influenza A infection. (a) Quantification of viral load determined using standard plaque assay ${ }^{*} P<0.05,{ }^{\star \star} P<0.01$, ${ }^{\star \star \star} P<0.001$ (day $6, n=5$ per group; day 8 and day $10, n=10$ per group. Determined by two-tailed Student's $t$-test. Data are representative of two independent experiments. Dashed line indicates the limit of the viral detection. (b) Representative photograph of lung hemorrhage, white dashed lines indicate the boundaries of lung hemorrhagic area (c) quantification of the hemorrhagic scores (\% of surface area), (d) lung weight at 6,8 , and 10-days post influenza A infection in the same group of mice described in (a). ${ }^{*} P<0.05$ ( $n=5$ to 15 per group) using the Student $t$ test with Bonferroni correction. 
effects of IL-17A inhibition in our preclinical model of smoke and influenza infection. WT mice were exposed to cigarette smoke or air for 3 months and were treated with anti-IL-17A antibody or control IgG2 every three days for 2 weeks, with the first dose given 3 days before influenza A infection (Supplementary Figure S10A). Neutralizing anti-IL-17 antibody treatment efficiently reduced available circulating IL-17A as determined by enzyme-linked immunosorbent assay (ELISA) of serum and BAL fluid in air- and smoke-exposed mice when compared with isotype control IgG2 treatment (Supplementary Figure S10B). Air/Flu mice treated with antiIL-17A antibody showed significantly improved recovery (e.g., less weight loss) when compared with isotype control antibodytreated mice (Figure 5a, left panel). Inhibition of IL-17A in Smk/Flu-treated mice did not result in improved recovery when compared with the isotype control group, indicating that downstream effects of IL-17A induction in the smoke group were not affected by late inhibition of this cytokine after infection (Figure 5a, right panel). Consistent with these observations there was a significant decrease in lung inflammatory cells in the BAL fluid (Figure 5b), lung histology (Figure $\mathbf{5 c}$ and $\mathbf{d}$ ), and hemorrhagic score in Air/ Flu but not Smk/Flu-treated mice with anti-IL-17A antibody (Figure 5e). Analysis of BAL fluid also showed reduced proinflammatory chemokines in Air/Flu mice that received antiIL-17A antibody, whereas smoke-exposed mice showed relatively similar cytokine and chemokine levels (e.g., KC, tumor necrosis factor- $\alpha$, and MCP-1) (Supplementary Figure S11A).

We next examined the relative abundance of $\mathrm{T}$ cells in each group and found that in vivo IL-17A blockade in the Air/Flu group resulted in significant increase in the relative abundance of $\gamma \delta$ T cells when compared with isotype control, whereas the Smk/Flu group showed no significant changes in this cell population (Figure 5f and g). As blocking IL-17 in smoketreated animals did not offer protection from influenza, we hypothesized that smoke altered the ability of $\gamma \delta \mathrm{T}$ cells to produce IFN- $\gamma$ after viral infection. To test this, we isolated lung $\mathrm{CD} 45^{+}$from influenza-infected mice exposed to smoke or air for 3 months. Cells were treated ex vivo with anti-IL-17A antibodies or isotype control antibodies for $24 \mathrm{~h}$. Consistent with the in vivo data, inhibition of IL-17A in air but not smokeexposed mice resulted in an increase in transcriptional expression of T-bet in $\gamma \delta \mathrm{T}$ cells, whereas no significant difference were noted in $\mathrm{CD} 4{ }^{+} \mathrm{T}$ cells and $\mathrm{CD} 45^{+} / \gamma \delta \mathrm{T}^{-} /$ $\mathrm{CD} 4^{-} \mathrm{T}$ cells (Figure $5 \mathbf{h}$ and $\mathbf{i}$ and Supplementary Figures S11 B and C and Supplementary Figures S12A-G). Together, these findings indicate that smoke-mediated induction of IL17A is critical for effective $\gamma \delta \mathrm{T}$ cell anti-viral IFN- $\gamma$ responses in the lungs.

$\gamma \delta \mathrm{T}$ cells are required for recovery from Influenza $A$ in smoke-exposed mice

Our findings indicate a reciprocal relation between IFN- $\gamma$ and IL-17A expression in recovery from acute influenza infection, whereby smoke-induced increased IL-17A expression in $\gamma \delta$ and
CD4 T cells leads to reduced IFN- $\gamma$ and decreased survival after influenza infection. As Il-17a $a^{-/-}$mice exposed to smoke and influenza showed attenuated lung injury and increased IFN- $\gamma$ expression especially in $\gamma \delta$ T cells, we next examined the role of $\gamma \delta$ T cells in the smoke-flu model. We had previously shown that $T c r \delta^{-1-}$ mice develop an exaggerated inflammatory phenotype when exposed to four months of smoke. ${ }^{21}$ Consistently, we found $T c r \delta^{-1-}$ Smk/Flu-treated mice exhibited significantly increased morbidity (as assessed by greater weight loss) (Figure 6a) and experienced higher mortality (30\% vs. $14 \%)$ when compared with WT mice treated the same way. Similar to Smk/Flu $I l-17^{-1-}$ mice, Smk/Flu Tcr $\delta^{-1-}$ mice showed transient increases in viral titers at peak infection (day 6), indicating that IL-17A derived from $\gamma \delta$ T cells has a critical role in early viral containment (Figure 6b). Further, we found increased inflammatory cells in the BAL of Smk/Flu $T c r \delta^{-/-}$ compared with WT mice (Figure 6c). Histological analyses demonstrated extensive tissue destruction and macrophage infiltration in the lungs of Smk/Flu $T c r \delta^{-/-}$mice (Figure 6d and e). To determine if lack of $\gamma \delta \mathrm{T}$ cells in mice exposed to smoke fail to induce viral specific $\mathrm{T}$ cell responses, we next examined IL-17A and IFN- $\gamma$ production in different T-cell subsets. ICC analyses of lung T cells showed no significant changes in CD4 and CD8 T cells expressing IL-17A in WT or $T c r \delta^{-1-}$ mice in Air/Flu or Smk/Flu group (Figure $6 \mathbf{f}$ and $\mathbf{g}$ ). Further, Smk/Flu group significant decrease in IFN- $\gamma$ in CD4 T cells in both WT and $T c r \delta^{-/-}$mice, whereas this response was also reduced in CD8 $\mathrm{T}$ cells in Smk/Flu group $\mathrm{Tcr} \delta^{-/-}$mice (Figure $\mathbf{6 g}$ ). In the absence of $\gamma \delta \mathrm{T}$ cells, both $\mathrm{CD} 4^{+} \mathrm{T}$ cells and $\mathrm{CD}^{+} \mathrm{T}$ cells show reduced IFN- $\gamma$ in the Smk/Flu-treated groups.

Despite the increase in inflammatory cells, we found decreased expression of IFN- $\gamma$ and its regulated genes (e.g., Irf7, Gzmb, etc.) and significant reduction of protective HA specific IgG and IgA in Smk/Flu-treated $T c r \delta^{-/-}$mice (Figure $7 \mathbf{a}$ and b). Similarly, lung homogenates of $T c r \delta^{-/-}$mice contained increased inflammatory cytokines (e.g., MCP-1 and IL-6), whereas anti-viral immune responses were significantly reduced (Figure 7c). Thus, in the context of smoke-exposed mice, lack of $\gamma \delta$ T cells limits production of IFN- $\gamma$ and related genes, lack of which correlates with poor survival after influenza infection.

\section{DISCUSSION}

Seasonal and pandemic influenza pneumonia account for the largest number of COPD exacerbations and hospitalizations, and are in turn, associated with increased mortality. ${ }^{32}$ Survival after acute lung infection heavily depends on the recruitment of specialized immune cells that resolve the infection while simultaneously protecting barrier functions in the lungs. ${ }^{39,40}$ Specifically, eradication of acute viral infections requires the rapid induction of type I IFNs to inhibit viral replication and reduce epithelial cell injury. ${ }^{8}$ Human respiratory epithelial cells and mice exposed to smoke fail to express protective type I IFNs in response to influenza infection, ${ }^{9,11,40}$ indicating the presence of suppressive factors in the lungs that could mediate poor 
immune responses. We found that WT mice exposed to chronic smoke developed exaggerated lung inflammation marked by enhanced IL-17A expression and respiratory failure when infected with influenza. Increased mortality and morbidity in these mice was associated with decreased type I and II IFNs expression, and reduced HA-specific antibody production that
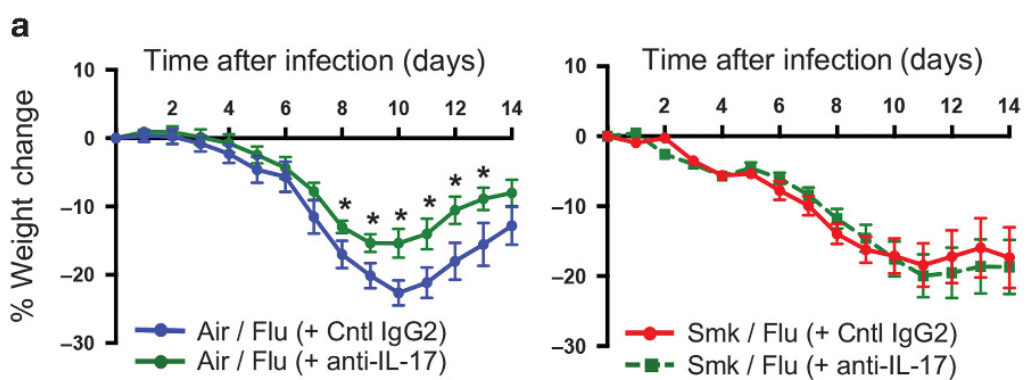

c
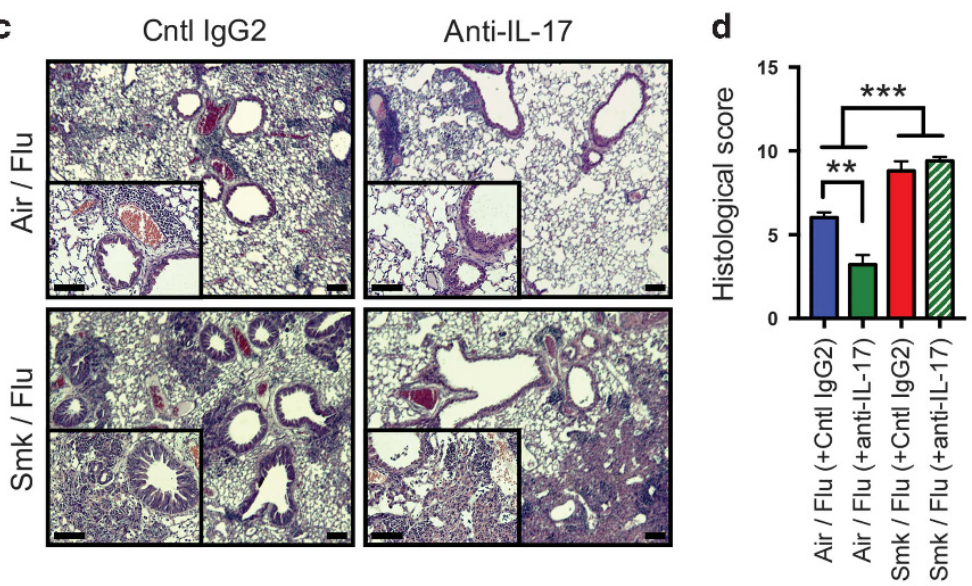

f
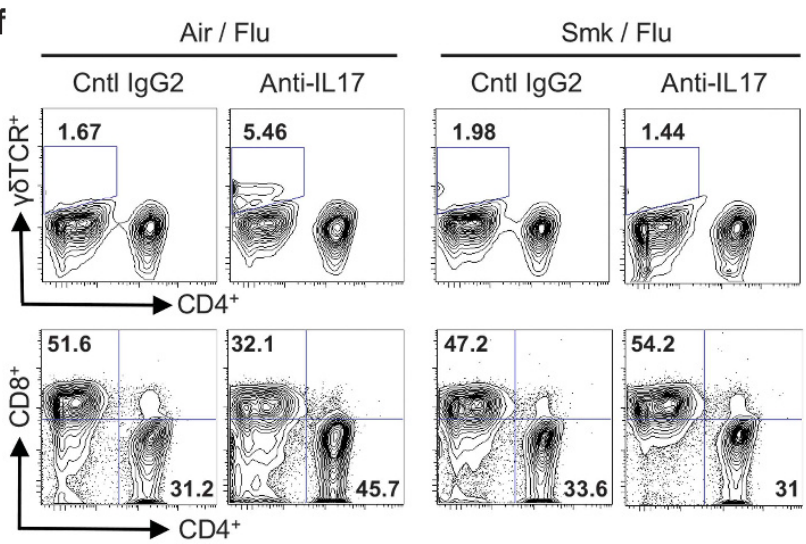

h
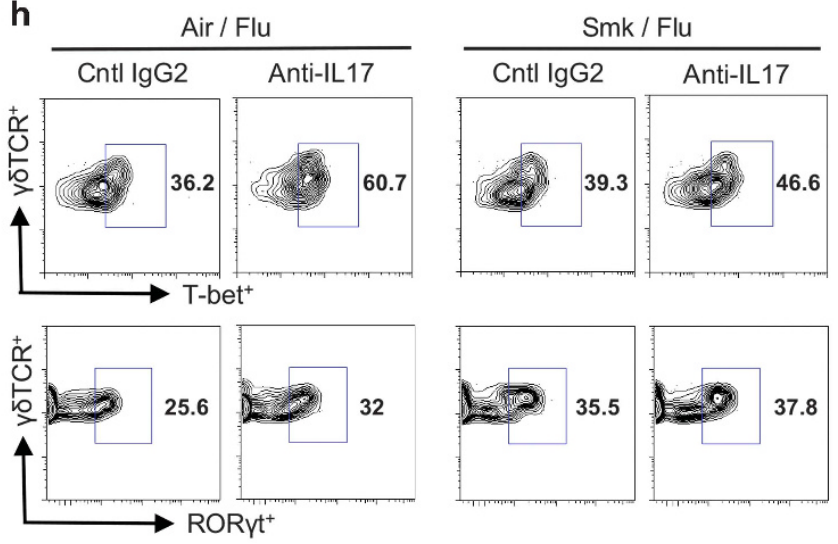
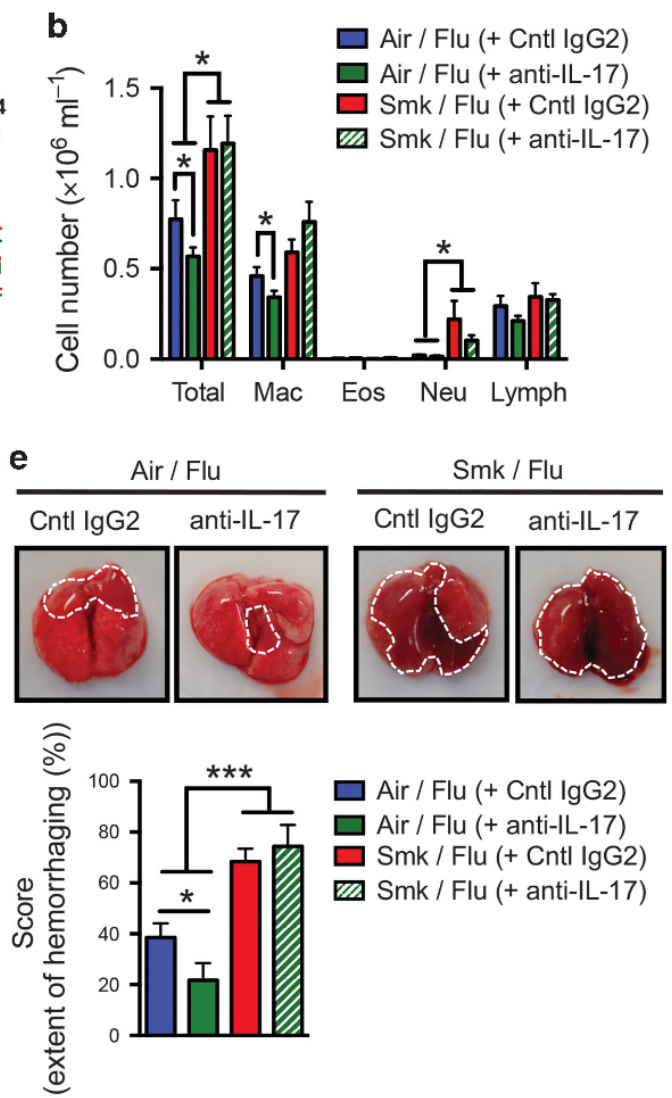

$\square$ Air / Flu (+ Cntl lgG2)

$\square$ Air / Flu (+ anti-IL-17)

$\square$ Smk / Flu (+ Cntl IgG2)

ש Smk / Flu (+ anti-IL-17)

g
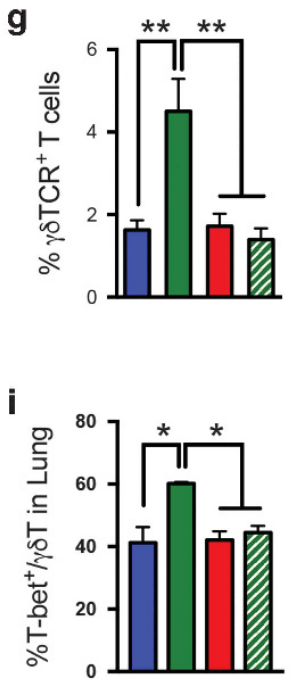

$\square$ Air / Flu (+ Cntl lgG2)

$\square$ Air / Flu (+ anti-IL-17)

$\square$ Smk / Flu (+ Cntl IgG2)

ש. Smk / Flu (+ anti-IL-17)

Air/Flu $(+\mathrm{Cntl} \lg \mathrm{G} 2)$

Dmk / Flu (+ anti-IL-17)

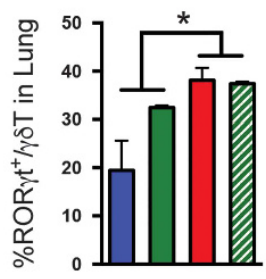


resulted in inadequate viral clearance during the late stage of influenza infection.

The primary intention of our protocol was to simulate behavior in addicted smokers who continue to smoke despite development of acute lower respiratory tract infection. Our findings (e.g., reduced anti-HA specific IgG, or IgA antibody, IFN- $\gamma$, and its related chemokines) suggest that chronic smoke significantly inhibits anti-viral responses. In a model of sidestream smoke and high-dose influenza infection, lung viral clearance was shown to remain intact, although smoke-exposed mice showed increased mortality, which was associated with increased tumor necrosis factor- $\alpha$, IL- 6 , and type 1 IFN expression. ${ }^{9}$ Although influenza-specific memory antibody formation in response to influenza re-challenge was not altered in that model, ${ }^{9}$ our studies reported here did not specifically examine the role of IL-17a in B-cell memory response to influenza re-infection. Whether global loss of IL-17a could provide better secondary immune response upon influenza rechallenge should be an interesting area of new investigation in the future.

Prior studies have shown that under homeostatic conditions, IL-17A has a limited role in acute influenza viral clearance, because IL-17RA deficient mice showed no defect when infected with influenza. ${ }^{41}$ We show here that under steady state conditions, IL-17A is minimally expressed by CD 4 and $\gamma \delta$ $\mathrm{T}$ cells in the airway mucosa, but after influenza infection, they express IFN- $\gamma$. However in response to cigarette smoke, lung both $\gamma \delta$ and $\alpha \beta$ population of $\mathrm{T}$ cells increase IL-17 production, ${ }^{24}$ which we show here blunts IFN- $\gamma$ responses after influenza infection. Notably, on day 6 post infection, we observed a transient decrease in influenza viral clearance in $\mathrm{Il}$ $17 a^{-/-}$mice; however, this difference was no longer evident by day 8 and influenza-related lung injury as measured by lung weight and hemorrhagic scores were significantly improved in smoke-exposed, infected Il-17a ${ }^{-/-}$mice. Together, these findings suggest that in this model of Smk/Flu treatment, absence of IL-17a promotes improved recovery and survival by day 14 post infection.

We and other have shown that $\gamma \delta \mathrm{T}$ cells represent less than $5 \%$ percent of total lung leukocytes, but their relative abundance is increased in response to chronic smoke exposure. $^{21,42}$ In influenza-infected animals, Irf7, a transcription factor that is critical for the induction of type I IFN production and recovery from primary influenza infection in humans is increased. ${ }^{40}$ The importance of this transcription factor in protection from acute viral infection has been underscored by the discovery of compound homozygous mutations in IRF7 in a patient who developed acute respiratory failure after primary influenza infection. ${ }^{34}$ In the context of COPD and active smoking with its associated chronic lung inflammation and loss of lung structural integrity, we found that smoke-exposed mice showed significantly reduced Irf7 expression after infection with influenza, whereas air-exposed, infected mice treated the same way showed a robust enhancement of this transcription factor. In response to chronic smoke exposure $\gamma \delta$ T cells produce increased IL-17A and lose the capacity to secrete IFN- $\gamma$ during Influenza $\mathrm{A}$ infection. IL-17 production has been shown to inhibit IFN $\gamma$ production by $\mathrm{CD} 4{ }^{+} \mathrm{T}$ cells in an autocrine manner. ${ }^{43} \mathrm{We}$ hypothesized that the enhanced IL-17 production after chronic smoke exposure reprogrammed $\gamma \delta \mathrm{T}$ cells inhibiting their ability to produce IFN- $\gamma$. Supporting this, IL-17A deficient mice showed intact immune response, expanded $\gamma \delta \mathrm{T}$ cell population which retain the ability to produce IFN- $\gamma$ after influenza infection despite chronic exposure to smoke. We also showed that exposure to smoke consistently inhibited Irf7 expression except in mice lacking IL-17A where its expression was independent of smoke exposure, indicating the inhibitory role of IL-17A in the regulation of Irf7 and both type I and Type II IFNs.

We have shown here that inhibition of IL-17A using blocking antibodies results in increased relative abundance of $\gamma \delta \mathrm{T}$ cells and enhanced type I IFNs production during Influenza A infection. Further, we have found that blocking IL-17A in lung $\mathrm{CD} 45^{+}$cells can reprogram $\gamma \delta \mathrm{T}$ cells in infected mice to increase $T$-bet expression. Conversely, exposure to cigarette smoke blocks this expression of $T$-bet. Together, these findings support a mechanism whereby chronic smoke exposure promotes persistent production of IL-17 by lung $\gamma \delta \mathrm{T}$ cells, while simultaneously inhibiting $T$-bet and IFN- $\gamma$ expression. However, as we used lung $\mathrm{CD} 45^{+}$cells in our in vitro assays, we speculate that inhibition of IL-17 under our culture conditions could be indirect. The exact mechanism(s) for this immune response in the lungs would be an interesting area of future investigation.

Although our studies confirm that both conventional CD4 $(\alpha \beta)$ and $\gamma \delta$ T cells predominantly express IL-17A in the lungs of mice exposed to smoke, and that these cells have nonredundant roles conferring protection against lethal Influenza A, we show here that $\gamma \delta$ T cells specifically protect against

Figure 5 Interleukin (IL)-17 inhibition improves influenza recovery. Wild-type (WT) mice were exposed to air (Air) or smoke (Smk) for three months and were infected with sublethal H3N2 per protocol (Supplementary Figure S9A). Mice were treated with anti-IL-17A or isotype control (Cntrl IgG2) $100 \mu \mathrm{g}$ per mouse for 3 days before flu infection and continued every 3 days for 2 weeks. (a) Percent body weight changes following influenza $(n=9$ or 10$)$. (b) Total BAL cell count and differential (macrophages (Mac), eosinophil (Eos), lymphocytes (Lym), and neutrophils (Neu)) in the same group of mice on day 14 following influenza infection described in $\mathbf{a}^{\star} P<0.05$ ( $n=8$ or 9 mice per group). (c) Representative hematoxylin and eosin (H\&E) stain of lung tissue section 14 days after influenza A infection and pathology score. (d) ${ }^{* *} P<0.01$, ${ }^{* * *} P<0.001$. Scale bar, $100 \mu \mathrm{m}$. (e) Representative lung hemorrhage (top) and cumulative scores (bottom) in the same group of mice. (f) Representative flow cytometry, and (g) cumulative data showing relative abundance of $\gamma \delta$, CD4, and CD8 T cells in the lungs $\left(n=6\right.$ in each group. ${ }^{* *} P<0.01$ (h) Representative, and cumulative (i) lung CD45 ${ }^{+}$cells isolated from Air/Flu and Smk/ Flu-exposed mice as described in (b), and were cultured with anti-IL-17 antibody (30 $\left.\mu \mathrm{g} \mathrm{ml}^{-1}\right)$ or isotype control (IgG2) for $24 \mathrm{hr}$. T-bet, and Ror $\gamma t$ expression in $\gamma \delta$ T cells were detected using flow cytometry. Results are mean \pm s.e.m ( $n=4$ per group). ${ }^{*} P<0.05$ using the Student's $t$-test with Bonferroni correction. 


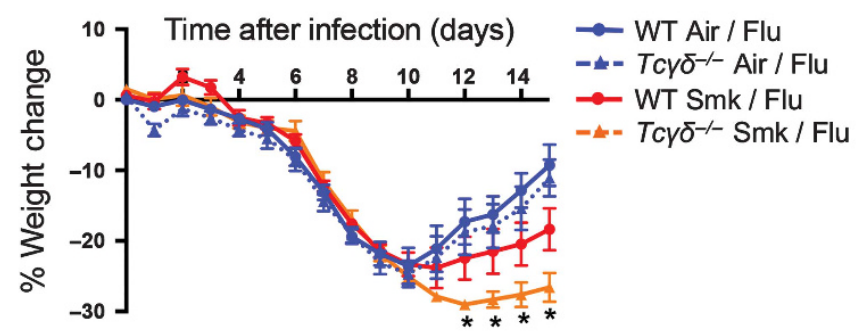

b

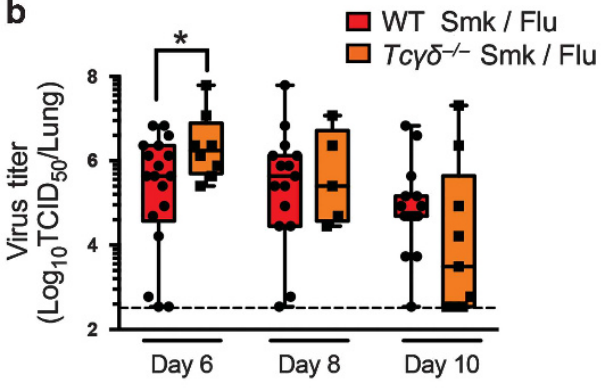

C

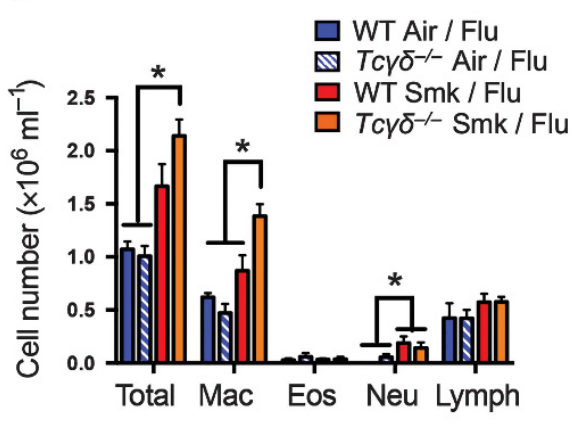

d

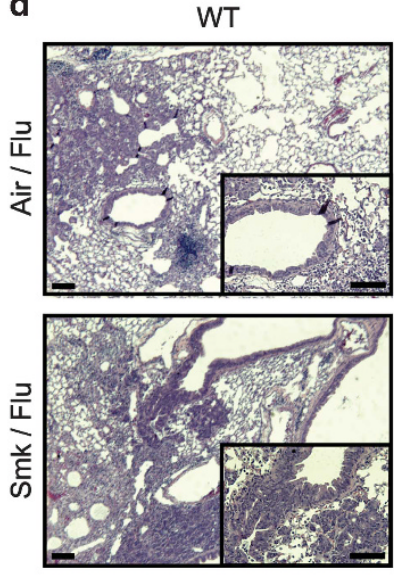

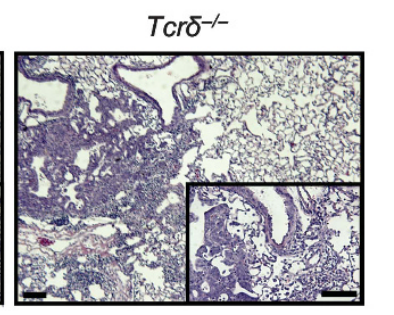

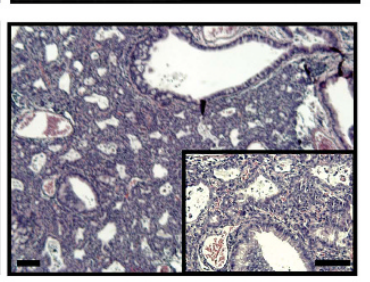

e

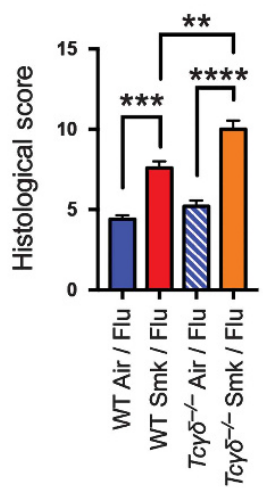

$\mathbf{f}$<smiles>O=S1(=O)C2CC3CCC(C2)CC1C3</smiles>
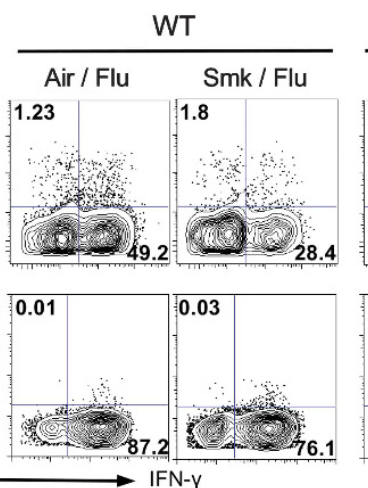
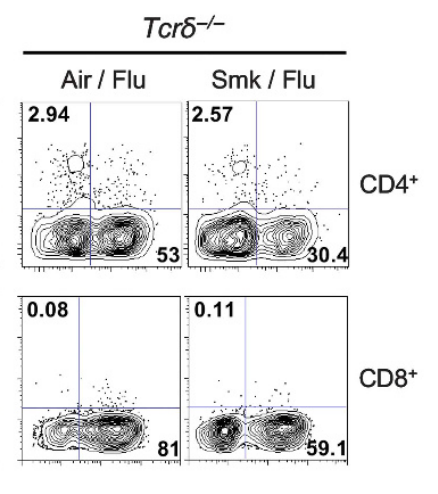

g

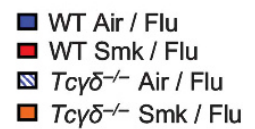

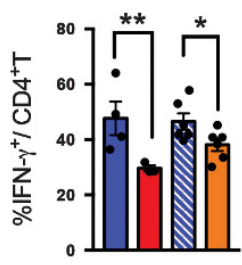

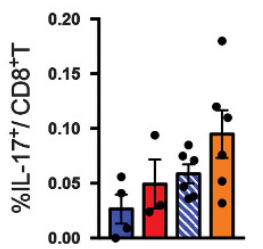

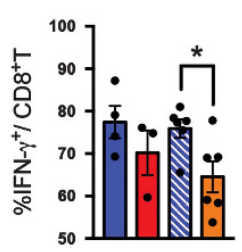

Figure 6 Increased mortality in Tcr $\delta^{-/-}$mice exposed to smoke and influenza. Wild-type (WT) and Tcr $\delta^{-/-}$mice were exposed to air (Air) or smoke (Smk) for 3 months and were infected with sub lethal H3N2 per protocol (Supplementary Figure S1A). (a) Body weight reduction (percent change) following influenza infection ( $n=7$ to 10 mice per group). Data (mean \pm s.e.m.) are representative of three independent studies using Pearson's correlation coefficient. (b) Quantification of viral load in the lung from mice (WT and $T c r \delta^{-1-}$ mice) in Smk/Flu groups. Data are presented as mean \pm s.e.m. and are representative of two independent experiments. ${ }^{*} P<0.05$. (c) Representative experiment showing total bronchoalveolar lavage (BAL) cell count and differential (macrophages (Mac), eosinophil (Eos), lymphocytes (Lym), and neutrophils (Neu)) in the same group of mice on day 14 following influenza infection described in (a) ( $n=4$ to 8 mice per group). (d) Representative hematoxylin and eosin (H\&E) stain of lung tissue section 14 days after influenza A infection and pathology score (e). Scale bars, $100 \mu \mathrm{m}$. ${ }^{\star \star} P<0.01,{ }^{\star \star \star} P<0.001$, ${ }^{\star \star \star \star} P<0.0001$ (f) Representative intracellular cytokine (ICC) staining analyses of lung $\mathrm{CD} 4^{+} \mathrm{T}, \mathrm{CD} 8^{+} \mathrm{T}$ cells gated on total lung $\mathrm{CD} 3^{+}$lymphocytes. (g) Cumulative data interleukin (IL)-17A and interferon (IFN)- $\gamma \%$ ICC in CD4, CD8 T-cell subsets isolated from the lungs in the same group of mice ( $n=3$ to 6 per group). ${ }^{*} P<0.05,{ }^{\star *} P<0.01$ using the Student's $t$-test with Bonferroni correction for multiple comparisons.

influenza pneumonia under aberrant (e.g., smoke-induced) lung inflammatory conditions. In our model, the absence of $\gamma \delta$ $\mathrm{T}$ cells resulted in worse outcomes in mice exposed to smoke and Influenza A as assessed by increased weight loss, mortality, lung inflammation and viral burden. We found $\gamma \delta$ T-celldeficient animals exposed to smoke had significantly compromised anti-viral immunity with reduced type I and II IFN production and failure to secrete HA specific antibody. In 
$\mathbf{a}$

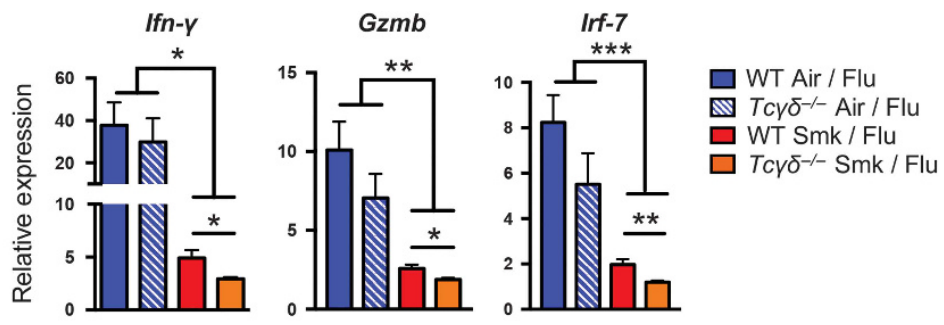

b
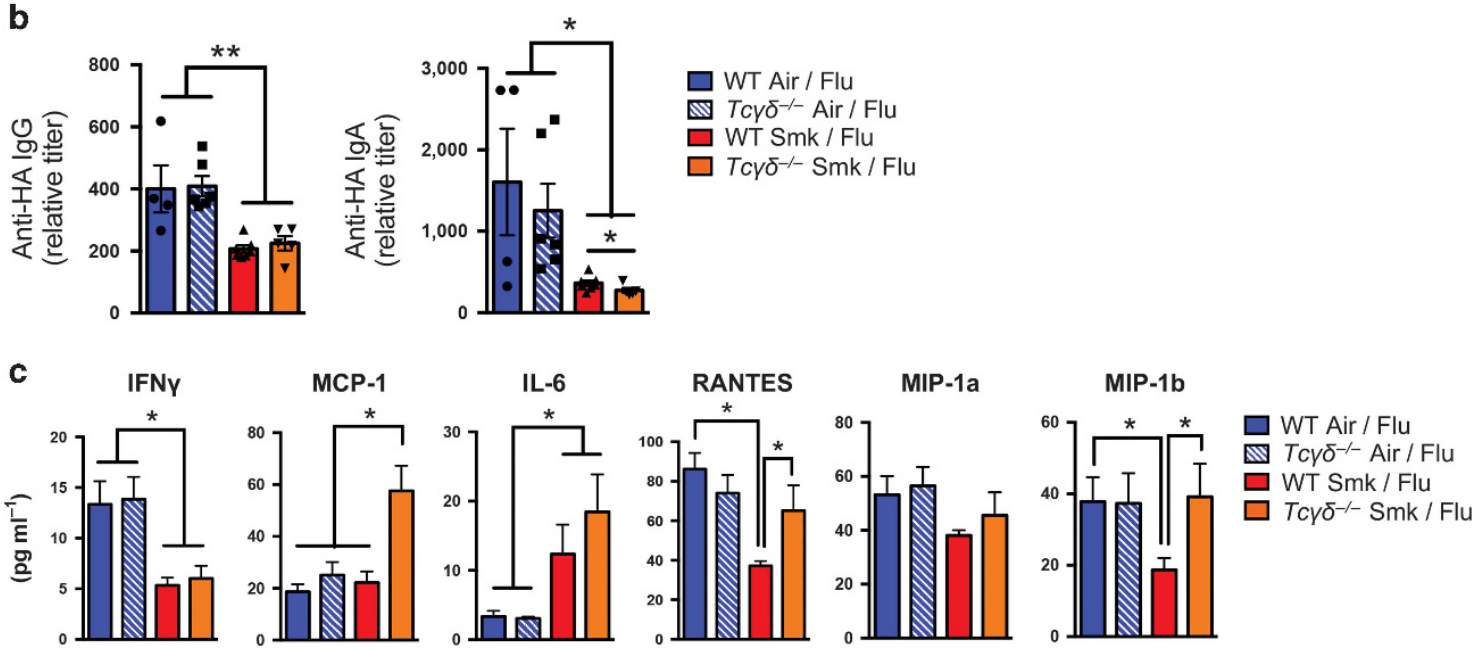

Figure 7 Reduced anti-viral immune responses in $T c r \delta^{-/-}$mice exposed to smoke and influenza. (a) Total lung mRNA expressions of Ifn- $\gamma$, Irf-7, and Gzmb at day 14 in the same group of mice on day 14 following influenza infection ( $n=4$ to 8 mice per group). ${ }^{*} P<0.05,{ }^{* \star} P<0.01,{ }^{* * *} P<0.001$. (b) Quantification of anti-hemagglutinin (HA)-specific IgG or IgA antibody using lung homogenates in the same four groups. Pooled data from two separate experiments are presented as mean \pm s.e.m. and significance was assessed using the Student's $t$-test. ${ }^{\star} P<0.05$, ${ }^{\star \star} P<0.01$ ( $n=4$ to 7 mice per group). (c) Selective cytokines and chemokines concentration was measured in lung homogenates using Multiplex assay in the same group ( $n=4$ to 8 mice per group). ${ }^{\star} P<0.05$ as determined using the Student's $t$-test with Bonferroni correction for multiple comparisons.

addition to their previously described role in controlling cytomegalovirus infection, ${ }^{44}$ our findings indicate that $\gamma \delta \mathrm{T}$ cells potentially have a critical role in recovery from influenza infection in smokers with COPD.

The protective role of $\gamma \delta \mathrm{T}$ cells were further confirmed in our preclinical model, because deletion of this subset of $\mathrm{T}$ cells resulted in exaggerated lung inflammation and death in mice exposed to smoke and influenza infection. Increased lung inflammation (e.g., macrophages and neutrophils) may have a significant role in increased mortality in $T c r \delta^{-/-}$mice treated in Smk/Flu model, but specific contribution of ineffective innate cells was not evaluated in this study. Together, our findings suggest a model, whereby cigarette smoke induces recruitment of activated $\gamma \delta$ T cells that are biased towards IL$17 \mathrm{~A}$ expression and fail to produce protective immunity in the context of influenza infection. In this scenario, smoke exposure promotes constitutive expression of IL-17A in $\gamma \delta \mathrm{T}$ cells, fail to produce IFN- $\gamma$ expression, which is required for induction of protective HA-specific antibodies. Consistent with our findings, a critical role for $\gamma \delta \mathrm{T}$ cells has been shown where immunodeficient mice reconstituted with human peripheral blood mononuclear cells (PMBCs) specifically expanded $\gamma \delta \mathrm{T}$ cells in response to aminobisphosphonate pamidronate treatment and showed enhanced immunity against influenza. ${ }^{45}$ The protective effect of pamidronate against influenza was lost in mice reconstituted with $\gamma \delta \mathrm{T}$ cells depleted human peripheral blood mononuclear cell. ${ }^{45}$

Smoke-induced IL-17 responses limit Th1 cell differentiation that is required for effective anti-viral protection. Mice exposed to smoke show baseline weight difference, which might, in part, account for the observation that following infection weight loss is more pronounced in the air group. The slope of average weight loss per day in flu-infected mice was similar in air or smoke-exposed group, and do not account for lack of appropriate immunological response to influenza infection. Notably, however, IL-17A-deficient mice exposed to smoke recovered faster from primary influenza infection, regained weight, and showed robust type I and II IFN responses in $\gamma \delta \mathrm{T}$ cells following influenza infection. Highlighting the detrimental impact of IL-17 in influenza responses, neutralizing antibody to IL-17A protected air-exposed mice from primary influenza pneumonia, whereas blocking IL-17 after smoke exposure did not offer similar protection. The mechanism for the protective effects of IL-17A neutralization was in part mediated through enhanced induction of $T$-bet and IFN- $\gamma$ in $\gamma \delta \mathrm{T}$ cells. Recovery of T-bet expression was not evident in cells from mice exposed to smoke demonstrating epigenetic changes induced by smoke that limit the immune system's ability to respond to subsequent challenges. Together, our findings highlight a novel immune mechanism underlying 
respiratory failure in smokers with COPD, and suggest that exploring natural and induced properties of $\gamma \delta \mathrm{T}$ cells in the lungs could provide new therapeutic option to treat viral infection in smokers.

\section{METHODS}

Mice. Female WT and Tcr $\delta^{-1-}$ mice (C57BL/6 background) were originally purchased from the Jackson Laboratory (Bar Harbor, ME) and all mice used in our experiments were bred at our facilities. $I l 17 a^{-1-}$ mice were acquired from Dr. Chen Dong's laboratory at University of Texas M. D. Anderson Cancer Center and were backcrossed six to eight generations to $\mathrm{C} 57 \mathrm{BL} / 6$ as we have described previously. ${ }^{21}$ All mice were bred in the transgenic animal facility at Baylor College of Medicine. All experimental protocols used in this study were approved by the Institutional Animal Care and Use Committee of Baylor College of Medicine and followed the National Research Council Guide for the Care and Use of Laboratory Animals.

Cigarette smoke exposure. Mice were exposed to cigarette smoke as we have previously reported. ${ }^{21,23}$ Six- to 8 -week-old female mice were exposed to active smoke from commercial cigarettes (Marlboro 100's). Exposure to 4 cigarettes (approximately 4 to $5 \mathrm{~min}$ per cigarette) per day, 5 days a week was carried out by intermittently forcing air $\left(41 \mathrm{~min}^{-1}\right)$ through the burning cigarette. Intermittent cycles were designed to mimic puffing cycles of actual human smokers and to prevent CO2-induced asphyxiation. Puffing cycles consisted of $5 \mathrm{~s}$ of active cigarette smoke followed by $25 \mathrm{~s}$ of forced air by a timercontrolled two-way valve (Humphrey, Kalamazoo, MI). Mice were given 10 min of rest between each cycle of cigarette smoke exposure. In total, mice were given 4 cigarettes each day $(1 \mathrm{~h}), 5$ days a week for 3 months. Specific details regarding our validated whole body smoke exposure are previously published. ${ }^{22}$ Two days following influenza infection, mice were exposed to two cigarettes each day for two additional 12 days; mice were killed 14 days following influenza infection.

Flow cytometry and antibodies. Flow cytometry was performed with a BD LSRII (BD Biosciences, San Jose, CA), and data were analyzed with FlowJo software (Tree Star, Inc, Ashland, OR). The following mouse-specific antibodies were purchased from BD Pharmingen (San Jose, CA): phycoerythrin (PE)-conjugated anti-IL-17A (559502), allophycocyanin-conjugated anti-IFN- $\gamma$ (554413), Pacific Blueconjugated anti-CD3e (558214), allophycocyanin-Cy7-conjugated anti-CD8a (557654), and PE-Cy5-conjugated anti-CD4 (553050). In addition, fluorescein isothiocyanate-conjugated anti- $\gamma \delta$ T-cell receptor (11-5711-82), PE-conjugated anti-ROR $\gamma \tau$ (12-6981-80), PE-conjugated anti-CD11b (12-0112-82), and allophycocyaninconjugated anti-CD11c (17-0114-82) were purchased from eBioscience (San Diego, CA). PE/Cy7-conjugated anti-Tbet (644824) from Biolegend (San Diego, CA). Goat Anti-Mouse Ig (H + L) (101001 ), horseradish peroxidase-conjugated secondary antibodies against mouse IgG (1130-05), and IgA (1140-05) for ELISA were purchased from Southern Biotechnology (Birmingham, AL). HA Recombinant Influenza A Virus protein, Subtype H3N2(A/Aichi/2/1968), and His Tag (11707V08H50) for HA-specific ELISA were purchased from Sino Biological Inc. (Beijing, China). Anti-IL-17A (CNTO8096) and isotype control (CNTO6601) rat/murine IgG2a/kappa were provided by Janssen R\&D (San Diego, CA).

Gelatin gel zymography. MMP2 and MMP9 proteins in BAL fluid were detected using gelatin zymography. ${ }^{46}$ Briefly, $10 \mu \mathrm{l}$ of BAL fluid was separated using $10 \%$ SDS-polyacrylamide/ $2 \%$ gelatin and were washed in $2.5 \%$ Triton $\mathrm{X}-100$ before incubation at $37^{\circ} \mathrm{C}$ in developing

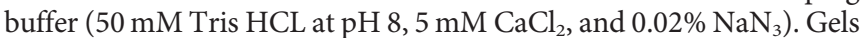
were then fixed and stained with 50\% methanol and 10\% acetic acid that contained $0.3 \% \mathrm{w} / \mathrm{v}$ Coomassie blue. MMP2 and MMP9 appear as clear bands at $\sim 68$ and $102 \mathrm{kDa}$, respectively. ${ }^{46}$
ICC staining and enzyme-linked immune-spot. Mouse lung RBCfree single-cell suspensions were stimulated with phorbol 12-myristate 13 -acetate $\left(10 \mathrm{ng} \mathrm{ml}^{-1}\right)$ (Sigma-Aldrich, St. Louis, MO), and ionomycin $\left(1 \mathrm{mg} \mathrm{ml}^{-1}\right)$ (Sigma-Aldrich) supplemented with brefeldin A $\left(10 \mathrm{mg} \mathrm{ml}^{-1}\right)$ (Sigma-Aldrich) for $6 \mathrm{~h}$. Cells were fixed with BD FACS lysing solution and then stained for surface markers with anti-CD3, anti-CD4, anti-CD8, and anti- $\gamma \delta$ TCR antibodies, and then fixed with $1 \%$ paraformaldehyde, permeabilized with $0.5 \%$ saponin (Sigma), and stained with anti-IFN- $\gamma$ and anti-IL-17A antibodies for analysis of ICC production by flow cytometry. Enzyme-linked immune-spot assay used to detect IFN- $\gamma$, IL-4, and IL-17 as we have previously described. ${ }^{47}$

mRNA isolation and quantitative PCR. Cell pellets were treated with TRIzol (Invitrogen, Carlsbad, CA), and mRNA was extracted with chloroform (Sigma-Aldrich), precipitated in isopropanol (Sigma-Aldrich), and washed in $70 \%$ alcohol (Sigma-Aldrich). The mRNA concentration was measured using Nano-Drop 2000 (Thermo Fisher Scientific, Waltham, MA). RNA was used to prepare cDNA with the High Capacity cDNA Reverse Transcription Kit (Applied Biosystems, Foster City, CA) and Real-time reverse-transcriptase PCR was performed using Taqman Universal PCR Master Mix with specific primers to determine relative gene expression using the $A B I$ PerkinElmer Prism 7500 Sequence Detection System (Applied Biosystems). The following primers of the analyzed genes were all purchased from Applied Biosystems: Ill7a (Mm00439619_m1), Ifn $\gamma$ (Mm01168134_m1), Mmp9 (Mm00600164_g1), Mmp12 (Mm00500554_m1), Irf7 (Mm00516788_m1), Ifit3(Mm01704846_s1), Ifnb1(Mm00439552_s1), and Gzmb(Mm00442834_m1). All data were normalized to $18 \mathrm{~S}$ ribosomal RNA (Hs99999901_s1) expression.

Sublethal influenza infection and anti-II-17A blocking antibody treatment. Sex and age-matched 6- to 8-week old mice with exposed to air or smoke were given influenza A/Hong Kong/8/68 (H3N2) (A/HK/ 68 ) at a sublethal dose of $25 \mathrm{TCID}_{50} /$ mouse using aerosol administration. ${ }^{48}$ A clinical isolate of influenza A/Hong Kong/8/68 (H3N2) (A/HK; Mouse Lung Pool) virus was stored as frozen stock $\left(2.8 \times 10^{7}\right.$ $\mathrm{TCID}_{50} \mathrm{ml}^{-1}$ ). Stock was diluted 1:1,000 in $0.05 \%$ gelatin in Eagle's minimal essential medium (Sigma-Aldrich) and animals were placed in an enclosed chamber and flu virus was aerosolized for $20 \mathrm{~min}$. Viral concentration in the nebulizer before and after aerosolization and in lung homogenates was determined by hemagglutination assay of infected Madin Darby canine kidney cells. Mouse weight changes, an indication of infection severity, recovery, and survival were monitored prior to and daily for 14 days post influenza infection. Mice were killed on day 14 unless indicated.

In selected experiments, mice were treated with $100 \mu \mathrm{g} / \mathrm{mouse}$ antiIL-17A (CNTO8096), or equal quantity of isotype control (CNTO6601) intraperitoneally ${ }^{49} 3$ days before influenza A inoculation and continued every 3 days for 2 weeks as described in Supplementary Fig S10A.

Determination of lung influenza viral titer. Some mice were killed on days 6,8 , and 10 after intranasal inoculation with influenza $A$ as we have previously reported; ${ }^{33}$ lungs were collected and rinsed in sterile water to lyse excess red blood cells. Lungs were placed in Dulbecco's modified Eagle's medium and homogenized using a glass bead beater (Biospec Products, Bartlesville, OK). Samples were diluted in Dulbecco's modified Eagle's medium containing $0.05 \%$ trypsin (Worthington Biochemical, Lakewood, NJ) were centrifuged for $10 \mathrm{~min}$ at 9,000 r.p.m. and supernatants were serially diluted in 96-well roundbottom plates (Fisher Scientific, Atlanta, GA). Samples were then transferred to 96-well round-bottom plates containing Madin Darby canine kidney cell monolayers. Lung dilutions and Madin Darby canine kidney cells were incubate for 4 days and then visualized for characteristic adherence of turkey red blood cells (Fitzgerald Industries, Concord, MA). 
Analysis of experimental model of COPD. Acellular BAL fluid collection and quantitation of airway cells were carried out as previously described. ${ }^{21}$ BAL fluid was collected using $0.8 \mathrm{ml}$ of sterile phosphate-buffered saline twice. Total and differential cell count in the BAL fluid were determined with the standard hemocytometer and HEMA3 staining (Biochemical Sciences, Inc, Swedesboro, NJ) of $200 \mu \mathrm{l}$ of BAL fluid prepared using the cytospin. ${ }^{21}$ Cytokine and chemokine concentrations in the BAL fluid and lung homogenate supernatant were measured with Milliplex kit (Millipore, Billerica, MA). In some experiments, mouse lungs were dissected and single-cell suspensions were cultured overnight to measure cytokines or were used directly to measure ICCs using the flow cytometer. Alternatively, some lungs were fixed with instillation of $4 \%$ paraformaldehyde solution via a tracheal cannula at $25 \mathrm{~cm} \mathrm{H}_{2} \mathrm{O}$ pressure followed by paraffin embedding and were sectioned for histopathological studies. Hematoxylin and eosin staining and Periodic Acid-Schiff staining were performed as described. ${ }^{21}$

Semi-quantitation of lung inflammation scores. Hematoxylin and eosin-stained slides were coded and scored from 0 (absent) to 4 (severe) for the following parameters: interstitial and endothelial inflammation, bronchitis, edema, thrombi, pleuritic, and percentage of the lung surface demonstrating confluent (diffuse) inflammatory infiltrate. ${ }^{50}$ The total lung inflammation score was expressed as the sum of the scores for each parameter.

Hemorrhagic score. Briefly quantification of lung hemorrhage was performed immediately after mice were euthanized at the indicated time points. Lung surface area were visually inspected by two blinded observers, and the extent of hemorrhage defined by percent of discolored lung surface area (e.g., from normal pink to maroon color) were scored using the following ranges: 0 (pink; no evidence of discoloration), 25, 50, 75, 100\% (complete maroon discoloration) $)^{37,38}$

Mouse immune cell isolation from lung, draining lymph nodes, and spleen. Mouse lung, draining lymph node, or spleen single-cell suspensions were prepared by mincing through a $40-\mu \mathrm{m}$ Falcon cell strainer, followed by RBC lysis (ACK lysis buffer) for $3 \mathrm{~min}$. To isolate lung allophycocyanins, RBC-free whole lung cells were labeled with paramagnetic bead-conjugated anti-CD11c (Miltenyi Biotec, Auburn, $\mathrm{CA}$ ) and isolated using autoMACS.

Mouse lung $\mathrm{CD}^{4} 5^{+}$cell isolation and IL-17 blocking studies. Singlecell suspensions of whole moue lung were prepared by mincing through a $40 \mu \mathrm{m}$ Falcon cell strainer, followed by RBC lysis (ACK lysis buffer) for $3 \mathrm{~min}$. Lung $\mathrm{CD} 45^{+}$cells were labeled using microbeadsconjugated to monoclonal anti-mouse CD45 (130-052-301, Miltenyi Biotec) and isolated using autoMACS separator. Sorted cells $\left(0.3 \times 10^{6}\right.$ cells per well) were cultured in the presence of anti-IL-17a $\left(30 \mu \mathrm{g} \mathrm{ml}^{-1}\right)$ or isotype control $\left(30 \mu \mathrm{g} \mathrm{ml}^{-1}\right)$ at $37^{\circ} \mathrm{C}$ for $24 \mathrm{~h}$. T-bet and Roryt expression in $\gamma \delta$ and $\mathrm{CD} 4 \mathrm{~T}$ cells were quantified using fluorescently labeling (PE/Cy7-T-bet or PE-Ror $\gamma$ t).

ELISA assay. Serial dilutions of lung homogenate supernatants were added to 96 -well plates coated with $5 \mu \mathrm{g} \mathrm{ml}^{-1}$ goat anti-mouse Ig $(\mathrm{H}+\mathrm{L})$ (Southern Biotechnology) and were incubated at room temperature for $2 \mathrm{~h}$, followed by incubation with horseradish peroxidase-conjugated secondary antibodies against mouse IgG (1:8,000 dilution) and IgA (1:2,000 dilution) (Southern Biotechnology). TMB Peroxidase Substrate Kit (Bio-Rad Laboratories, Hercules, CA) was used for detection of bound antibodies, and optical densities at $450 \mathrm{~nm}$ were measured. Influenza A H3N2-specific antibodies in the lung homogenate supernatants were measured similarly as above, except that 96-well plates were coated with $2 \mu \mathrm{g} \mathrm{ml}^{-1} \mathrm{H} 3 \mathrm{~N} 2 \mathrm{HA}$ (Sino Biological) and detected. A mixture of lung homogenates from WT smoke exposure mice infected with influenza virus A was used to establish standard curves in each plate, and antibody levels were shown as relative titers.
Statistical analyses. For the comparison of cytokine production and gene expression from air- or smoke-exposed and with- or withoutinfluenza virus infection mice, we used the Student's t test or one-way analysis of variance and Bonferroni's correction for multiple comparison. All statistical analyses were performed with GraphPad Prism (Graph-Pad Software, La Jolla, CA). The Student's $t$-test was performed using two-tailed parameters and a $P$-value of $<0.05$ was considered significant. All data shown are the mean \pm s.e.m.

SUPPLEMENTARY MATERIAL is linked to the online version of the paper at http://www.nature.com/mi

\section{ACKNOWLEDGMENTS}

This work was supported by the R01HL117181-01, (F.K., D.B.C.), CX000104 (F.K.), CX000 (D.B.C.), VA Merit Awards and DAMD W81XWH-16-1-0361 (F.K.), and DAMD W81XWH-16-1-0360 (MC), R01Al125264, and R21Al123945 (G.D.). This project was supported by the Cytometry and Cell Sorting Core at Baylor College of Medicine with funding from the $\mathrm{NIH}$ (AI036211, CA125123, and RR024574) and the expert assistance of Joel M. Sederstrom.

\section{AUTHOR CONTRIBUTIONS}

M.J. H. carried out experiments, collected and analyzed data, and assisted with manuscript preparation. B.H.G., M.C.M., M.K., C.M., X.Y., R.Y., and L.S. assisted with smoke exposure experiments. A.A.M. and B.E.G. assisted with flu exposure protocol and viral titer measurement. P.S. and M.E. provided anti-IL-17 antibody reagent and treatment protocol. M.C., D.B.C., G.D., and F.K. designed experiments, analyzed data, and prepared the manuscript.

\section{DISCLOSURE}

The authors declare no conflict of interest.

c) 2018 Society for Mucosal Immunology

\section{REFERENCES}

1. Wang, C.S., Wang, S.T., Lai, C.T., Lin, L.J. \& Chou, P. Impact of influenza vaccination on major cause-specific mortality. Vaccine 25, 1196-1203 (2007).

2. Wong, C.M. et al. Cigarette smoking as a risk factor for influenzaassociated mortality: evidence from an elderly cohort. Influenza Other Respir. Viruses 7, 531-539 (2013).

3. Noah, T.L., Zhou, H. \& Jaspers, I Alteration of the nasal responses to influenza virus by tobacco smoke. Curr. Opin. Allergy Clin. Immunol. 12, 24-31 (2012).

4. Horvath, K.M., Brighton, L.E., Herbst, M., Noah, T.L. \& Jaspers, I. Live attenuated influenza virus (LAIV) induces different mucosal Tcell function in nonsmokers and smokers. Clin. Immunol. 142, 232-236 (2012).

5. Arcavi, L. \& Benowitz, N.L. Cigarette smoking and infection. Arch. Intern. Med. 164, 2206-2216 (2004).

6. You, R. et al. Nanoparticulate carbon black in cigarette smoke induces DNA cleavage and Th17-mediated emphysema. Elife 4, e09623 (2015).

7. Sun, J. \& Braciale, T.J. Role of T cell immunity in recovery from influenza virus infection. Curr. Opin. Virol. 3, 425-429 (2013).

8. Hufford, M.M., Kim, T.S., Sun, J. \& Braciale, T.J. The effector Tcell response to influenza infection. Curr. Top. Microbiol. Immunol. 386, 423-455 (2015).

9. Robbins, C.S. et al. Cigarette smoke impacts immune inflammatory responses to influenza in mice. Am. J. Respir. Crit. Care Med. 174, 13421351 (2006).

10. Wu, W. et al. Cigarette smoke attenuates the RIG-I-initiated innate antiviral response to influenza infection in two murine models. Am. J. Physiol. Lung Cell Mol. Physiol. 307, L848-L858 (2014).

11. Gualano, R.C. et al. Cigarette smoke worsens lung inflammation and impairs resolution of influenza infection in mice. Respir. Res. 9, 53 (2008).

12. Herold, S. et al. Lung epithelial apoptosis in influenza virus pneumonia: the role of macrophage-expressed TNF-related apoptosis-inducing ligand. J. Exp. Med. 205, 3065-3077 (2008) 
13. Wortham, B.W. et al. NKG2D mediates NK cell hyperresponsiveness and influenza-induced pathologies in a mouse model of chronic obstructive pulmonary disease. J. Immunol. 188, 4468-4475 (2012).

14. Kang, M.J. et al. Cigarette smoke selectively enhances viral PAMP- and virus-induced pulmonary innate immune and remodeling responses in mice. J. Clin. Invest. 118, 2771-2784 (2008).

15. Hsu, A.C. et al. Targeting PI3K-p110alpha suppresses influenza virus infection in chronic obstructive pulmonary disease. Am. J. Respir. Crit. Care Med. 191, 1012-1023 (2015).

16. Beckham, J.D. et al. Respiratory viral infections in patients with chronic, obstructive pulmonary disease. J. Infect. 50, 322-330 (2005).

17. Brass, A.L. et al. The IFITM proteins mediate cellular resistance to influenza A H1N1 virus, West Nile virus, and dengue virus. Cell 139, 1243-1254 (2009).

18. McKinstry, K.K. etal. IL-10 deficiency unleashes an influenza-specific Th17 response and enhances survival against high-dose challenge. J. Immunol. 182, 7353-7363 (2009).

19. Ciancanelli, M.J., Abel, L., Zhang, S.Y. \& Casanova, J.L. Host genetics of severe influenza: from mouse Mx1 to human IRF7. Curr. Opin. Immunol. 38, 109-120 (2016).

20. Van Pottelberge, G.R. et al. Selective accumulation of langerhans-type dendritic cells in small airways of patients with COPD. Respir. Res. 11, 35 (2010).

21. Shan, M. et al. Cigarette smoke induction of osteopontin (SPP1) mediates $\mathrm{T}(\mathrm{H}) 17$ inflammation in human and experimental emphysema. Sci. Transl. Med. 4, 117 ra119 (2012).

22. Shan, M. et al. Agonistic induction of PPAR reverses cigarette smokeinduced emphysema. J. Clin. Invest. 124, 1371-1381 (2014).

23. Yuan, $X$. et al. Activation of $\mathrm{C} 3 a$ receptor is required in cigarette smokemediated emphysema. Mucosal Immunol. 8, 874-885 (2015).

24. Shan, M. et al. Lung myeloid dendritic cells coordinately induce $\mathrm{TH} 1$ and TH17 responses in human emphysema. Sci. Transl. Med. 1, 4ra10 (2009).

25. Grumelli, S. et al. An immune basis for lung parenchymal destruction in chronic obstructive pulmonary disease and emphysema. PLoS Med. 1, e8 (2004).

26. Lappalainen, U., Whitsett, J.A., Wert, S.E., Tichelaar, J.W. \& Bry, K. Interleukin-1beta causes pulmonary inflammation, emphysema, and airway remodeling in the adult murine lung. Am. J. Respir. Cell Mol. Biol. 32, 311-318 (2005)

27. Demoor, T. et al. CCR7 modulates pulmonary and lymph node inflammatory responses in cigarette smoke-exposed mice. J. Immunol. 183, 8186-8194 (2009).

28. Ravi, A.K. et al. Increased levels of soluble interleukin-6 receptor and CCL3 in COPD sputum. Respir. Res. 15, 103 (2014).

29. CDC. Smoking-attrib utablemortality, years of potential life lost, and productivity losses - UnitedStates, 2000-2004. Morb. Mortal. Wkly Rep. 57, 1226-1228 (2008).

30. Drews, A.L. et al. Dual respiratory virus infections. Clin. Infect. Dis. 25, 1421-1429 (1997).

31. Greenberg, S.B., Allen, M., Wilson, J. \& Atmar, R.L. Respiratory viral infections in adults with and without chronic obstructive pulmonary disease. Am. J. Respir. Crit. Care Med. 162, 167-173 (2000).
32. Greenberg, S.B. \& Atmar, R.L. Chronic airway disease: the infection connection. Trans. Am. Clin. Climatol. Assoc. 110, 38-48. discussion 4950 (1999).

33. Chen, M. et al. Essential role for autophagy in the maintenance of immunological memory against influenza infection. Nat. Med. 20, 503510 (2014).

34. Ciancanelli, M.J. et al. Infectious disease. Life-threatening influenza and impaired interferon amplification in human IRF7 deficiency. Science 348, 448-453 (2015).

35. Frasca, D. \& Blomberg, B.B. B cell function and influenza vaccine responses in healthy aging and disease. Curr. Opin. Immunol. 29C, 112118 (2014).

36. Grund, S., Pietzonka, S., Michel, S. \& Adams, O. Serum antibodies against native and denaturated hemagglutinin glycoproteins detected by ELISA as correlates of protection after influenza vaccination in healthy vaccinees and in kidney transplant recipients. J. Virol. Methods 193, 558-564 (2013).

37. Sidwell, R.W. et al. Efficacy of orally administered T-705 on lethal avian influenza A (H5N1) virus infections in mice. Antimicrob Agents Chemother 51, 845-851 (2007).

38. Smee, D.F., Barnard, D.L. \& Jones, S.M. Activities of JNJ63623872 and oseltamivir against influenza $\mathrm{A} \mathrm{H} 1 \mathrm{~N} 1 \mathrm{pdm}$ and $\mathrm{H} 3 \mathrm{~N} 2$ virus infections in mice. Antiviral Res. 136, 45-50 (2016).

39. Seo, S.H. \& Webster, R.G. Tumor necrosis factor alpha exerts powerful anti-influenza virus effects in lung epithelial cells. J. Virol. 76, 1071-1076 (2002).

40. Jaspers, I. et al. Reduced expression of IRF7 in nasal epithelial cells from smokers after infection with influenza. Am. J. Respir. Cell Mol. Biol. 43, 368-375 (2010).

41. Crowe, C.R. et al. Critical role of IL-17RA in immunopathology of influenza infection. J. Immunol. 183, 5301-5310 (2009).

42. Narayan, K. et al. Intrathymic programming of effector fates in three molecularly distinct gammadelta T cell subtypes. Nat. Immunol. 13, 511518 (2012).

43. O'Connor, W. Jr. et al. A protective function for interleukin 17A in T cellmediated intestinal inflammation. Nat. Immunol. 10, 603-609 (2009).

44. Willcox, C.R. et al. Cytomegalovirus and tumor stress surveillance by binding of a human gammadelta $T$ cell antigen receptor to endothelial protein C receptor. Nat. Immunol. 13, 872-879 (2012).

45. Tu, W. et al. The aminobisphosphonate pamidronate controls influenza pathogenesis by expanding a gammadelta T cell population in humanized mice. J. Exp. Med. 208, 1511-1522 (2011).

46. Hong, J.-S. et al. Dual protective mechanisms of matrix metalloproteinases 2 and 9 in immune defense against Streptococcus pneumoniae. J. Immunol. 186, 6427-6436 (2011).

47. Porter, P.C. et al. Airway surface mycosis in chronic TH2-associated airway disease. J. Allergy Clin. Immunol. 134, 325-331.e329 (2014).

48. Tai, W. et al. Multistrain influenza protection induced by a nanoparticulate mucosal immunotherapeutic. Mucosal Immunol. 4, 197-207 (2011).

49. Nakajima, K. et al. Distinct roles of IL-23 and IL-17 in the development of psoriasis-like lesions in a mouse model. J. Immunol. 186, 4481-4489 (2011).

50. Soltzberg, J. et al. Quantitative microscopy in murine models of lung inflammation. Anal. Quant. Cytol. Histol. 33, 245-252 (2011). 